\title{
Health Seekers' Acceptance and Adoption Determinants of Telemedicine in Emerging Economies
}

\author{
Khondker Mohammad Zobair \\ Griffith University, Brisbane, Australia \\ k.zobair@griffith.edu.au
}

\section{Louis Sanzogni}

Griffith University, Brisbane, Australia

\section{Luke Houghton,}

Griffith University, Brisbane, Australia

\author{
Kuldeep Sandhu \\ Griffith University, Brisbane, Australia
}

\section{Md Jahirul Islam}

Griffith University, Brisbane, Australia

\section{Abstract}

This study investigates health seekers' acceptance and adoption determinants of telemedicine services in a rural public hospital setting in an emerging economy using an adapted, extended Technology Acceptance Model. The present study pursued synthesising a plethora of existing literature and contextualised the significance of seven broad categories of potential determinants that significantly affect patients' acceptance and adoption intentions: perceived usefulness, perceived ease of use, self-efficacy, service quality, privacy and data security, social influence, and facilitating conditions. The partial least square structural equation modeling technique was employed to test the conceptual model and research hypotheses. A crosssectional survey was administered among 500 telemedicine users in randomly selected rural and remote areas of Bangladesh. Excluding self-efficacy and ease of use, five determinants expressively contributed to patients' acceptance of telemedicine adoption, explaining $65 \%$ of the variance $\left(R^{2}\right)$ in behavioural Intention. The empirical findings have the quality of rigour obtained from rich data sets in health informatics and can contribute to build telemedicine into an institutionalised health infrastructure in Bangladesh and similar settings. Pertinent implications, limitations and future research directions were recommended to secure the longterm sustainability of telemedicine healthcare projects.

Keywords: Acceptance, ICT, PLS-SEM, rural and remote areas, technology acceptance model, telemedicine

\section{Introduction}

Telemedicine emerges as a vital healthcare provision for rural and remote communities in many emerging economies where specialist physicians rarely practice (Zobair, Sanzogni, Sandhu, \& Islam, 2020). The widespread expansion of telemedicine potentially reduces health disparity between rural and urban areas (LeRouge \& Garfield, 2013), increases users' convenience (Zobair, Sanzogni, \& Sandhu, 2019), enhances accessibility and service quality, decreases healthcare costs (Jansen-Kosterink, Dekker-van Weering, \& van Velsen, 2019), and contributes to sustainable health care systems (Whitten, Holtz, \& Nguyen, 2010). While telemedicine healthcare services are well accepted by many clinicians and patients in both 
developed and emerging economies (Greenberg et al., 2019; Jansen-Kosterink et al., 2019), their adoption into routine practices are isolated, scattered (LeRouge, Gupta, Corpart, \& Arrieta, 2019) and slower than anticipated (Taylor, Coates, Wessels, Mountain, \& Hawley, 2015).

Telemedicine continues to gain significant recognition in providing specialised care to the rural and remote communities in Bangladesh. This service has formally been integrated in 2010 into its' public healthcare systems to deliver specialised care to rural and remote areas where around $70 \%$ of the population inhabits (Darkwa, Newman, Kawkab, \& Chowdhury, 2015; Zobair et al., 2019). Despite Bangladesh's passion for public telemedicine schemes, the functional adoption into clinical practices has remained inadequate in rural settings. The incorporation of 27 specialised, and district-level medical colleges and hospitals consistently providing specialist care to 488 Upazila (i.e., sub-district) public hospitals aided rural telemedicine centres is considered a momentous shift in the public healthcare sector in Bangladesh (Zobair et al., 2019).

The underlying principle of personalised healthcare approaches reflects the control patients exercise over their healthcare progress rather than the physicians themselves (Hur, Cousins, \& Stahl, 2019). Although many health providers facilitate a variety of ICT supported services (i.e., telemedicine/eHealth, mHealth), patients can actively participate in choosing what is more appropriate and convenient to them (Hur et al., 2019). Hence, it is mandatory to understand patients' evaluations of service quality that form their acceptance of the services. Exploration of health seekers' acceptance determinants in rural settings could support successful telemedicine implementation (Evans, 2015). The Technology Acceptance Model (TAM) is a fitting theory for understanding health information technology acceptance and adoption (Holden \& Karsh, 2010) in varieties of information-driven settings (i.e., telemedicine) that serve as the focus of this study.

Evidence suggests that, as modern healthcare services are becoming heavily reliant on technology, a better understanding of the determinants that contribute to acceptance and adoption of technology-mediated healthcare services (i.e., telemedicine) is now critical (Jewer, 2018). Understanding users' acceptance or rejection of technology, such as computers, appears to be one of the most challenging factors in information systems research (Davis et al., 1989). Given the importance of this issue, academic and practitioner literature has drawn on many behavioural theories, including the TAM (Agarwal et al., 2000). Likewise, some other classic theories that can be called upon to provide varying explanations of consumers' continuity behaviours towards technology adoption such as, the Theory of Reasoned Action; the Diffusion of Innovation Theory; Social Cognitive Theory; the Theory of Planned Behaviour; the Technology Acceptance Model; and the Unified Theory of Acceptance and Use of Technology (Hoque \& Sorwar, 2017; Leung \& Chen, 2019). Telemedicine health technology, like any innovative technology, faces critical issues related to stakeholders' acceptance and adoption (Zhou et al., 2019). Abundant empirical evidence further suggested that patients' past positive experiences and satisfaction affect their behavioural intention to use telemedicine services (Zhou et al., 2019). In the present study, patients' behavioural intentions to use telemedicine refers to acceptance and adoption (Holden \& Karsh, 2010).

Past contributions concerning studies in Bangladesh have mostly focused on m-Health adoption (Ahmed et al., 2014; Alam, Hoque, Hu, \& Barua, 2020; Hoque \& Sorwar, 2017), with a recent study (Hoque \& Sorwar, 2017) focusing on e-Health adoption in urban areas. Telemedicine appears to be well accepted by rural health seekers in many developed countries 
(Bros et al., 2018). Conversely, its acceptance by rural health seekers in developing countries could be based on different determinants that affect patients' behavioural intentions (Lin \& Chang, 2018). The existing literature has not yet identified these determinants associated with telemedicine in rural Bangladesh' public hospital settings. Little attention has been paid to exploring how public hospitals in Bangladesh can successfully provide telemedicine support to rural communities. Moreover, there have been little-reported investigations into telemedicine project initiation under the health authorities, representing a considerable knowledge gap. Employing a theory focused approach to examine ways to determine patients' acceptance/adoption of telemedicine could advance a rational understanding of how to sustain and leverage telemedicine deployment in rural Bangladesh settings. Motivated by prior technology adoption theory-based research, the current study aims to fill the literature gaps by empirically testing the suitability of the revised version of extended TAM framework as applied to the perceptions of Bangladeshi rural telemedicine patients.

\section{Theoretical Model and Hypotheses}

This study builds on prior research (Davis, 1989; Venkatesh, 2000a; Venkatesh \& Bala, 2008; Venkatesh \& Davis, 1996, 2000; Venkatesh, Morris, Davis, \& Davis, 2003) by presenting behavioural attributes while maintaining the parsimony of the original theory. Adapted from the theory of reasoned action, TAM is an extensively applied model used for predicting users' technology acceptance and usage (Venkatesh, 2000a, 2000b) by evaluating their internal beliefs, attitudes, and behavioural intentions (Davis, Bagozzi, \& Warshaw, 1989; $\mathrm{Hu}$, Chau, Sheng, \& Tam, 1999; Rho, young Choi, \& Lee, 2014). Venkatesh and Davis (2000) further proposed an extended TAM referred to as TAM 2, which together with TAM 3 (Venkatesh \& Bala, 2008), present a complete nomological network of the determinants of an individual' technology adoption and use (Venkatesh \& Bala, 2008). Although the TAM was initially applied to health information technology (HIT) adoption it has found its way into the health sector as a means to measure end-user reactions to HIT (Anderberg, Eivazzadeh, \& Berglund, 2019). The present study's rationale for the extension and integration of the TAM theory (Venkatesh \& Bala, 2008) was to establish a framework to predict health seekers' telemedicine acceptance and adoption determinants in developing countries' rural settings.

Cimperman, Brenčič, and Trkman (2016) argue that most of the prior studies often ignored some critical aspects concerning interdependency between human characteristics, technology, and socio-economic phenomena, which lead to low impact on healthcare practices. Cimperman et al. (2016) further suggest that the previously developed TAM theory should be extended by adding those factors for the plausibility of the existing theory. In a recent study, for example, Zhou et al. (2019) adopted an extended TAM to explore the determinants of the behavioural intention of telehealth adoption among older adults in China. Synthesising prior TAM studies related to the health IT adoption, we developed an extended TAM (Venkatesh \& Bala, 2008). A plethora of telemedicine, e-Health, and m-Health studies (Alam et al., 2020; Chau \& Hu, 2002; Hoque \& Sorwar, 2017; Zhou et al., 2019), provide a solid theoretical foundation for the extended TAM. Jansen-Kosterink et al. (2019), for instance, revealed that TAM was employed for examining users' telemedicine acceptance and could explain up to $70 \%$ of the variance in individuals' acceptance intentions. Coherently and cogently to this background, this study adopted seven common categories of determinants adapted from prior studies (see Appendix A) for predicting health seekers' telemedicine acceptance and adoption intention in rural Bangladesh's public hospital settings (see Figure 1). 


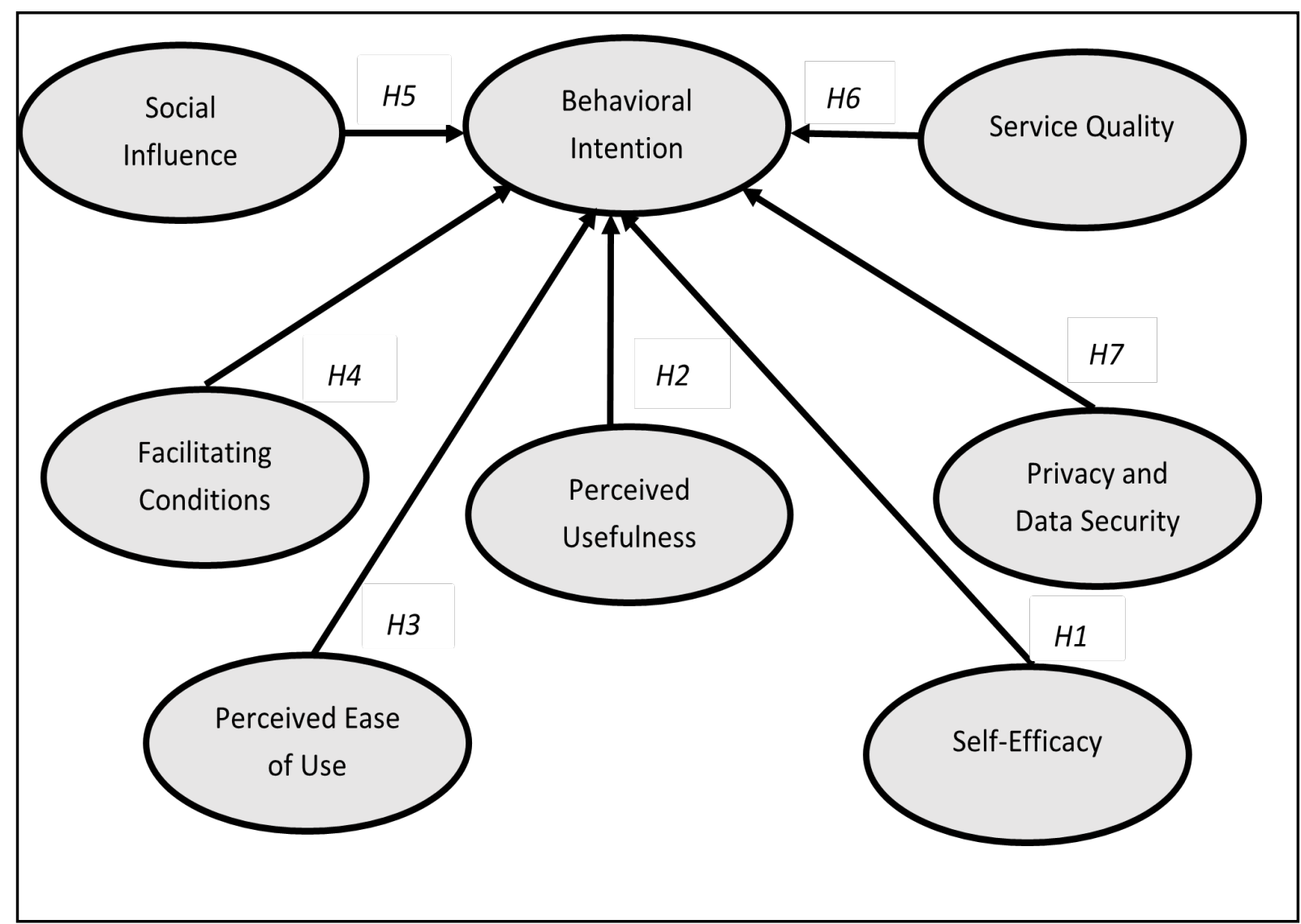

Figure 1. Research model

\subsection{Self-Efficacy}

Self-efficacy comprises individuals' judgements of their abilities to perform given levels of performance and control over the events (Bandura, O'Leary, Taylor, Gauthier, \& Gossard, 1987). An individual's perceived self-efficacy has a direct influence on his/her choice of activities (Bandura, 1977). Within the telemedicine context, self-efficacy refers to the extent of an individual's judgment concerning his or her capability to attain a certain degree of telemedicine service performance (Zobair et al., 2019). Although, it does not explicitly comprise patients' perceptions of their skills in physical experiences of telemedicine technology (Zobair et al., 2019). Perceived self-efficacy in telemedicine combines the patients' assessment of the effectiveness of services performance and the ability or competency to conduct the behaviour (Zhang et al., 2017). For example, within the health context, Bandura (1986) confirmed that perceived self-efficacy arbitrates patients' health behaviours. Bandura et al. (1987) found that perceived self-efficacy has positively influenced patients' coping mechanisms related to pain alleviation. Within the health context, Williams and Bond (2002) confirmed that self-efficacy is the strongest predictor of diabetic patients' behavioural intention. Self-efficacy comprises a multiplicity of skills that affect individuals' belief that they can execute particular tasks in specific situations (Rosenstock, Strecher, \& Becker, 1988), such as information systems acceptance and adoption (Lending \& Dillon, 2007). Consistent with prior studies, it is predicted that highly efficacious patients incline to have a high intention to accept telemedicine services (Zobair et al., 2019). Therefore, the following hypothesis is proposed: 
H1: Self-efficacy positively influences patients' behavioural intentions to use telemedicine health services.

\subsection{Perceived Usefulness}

Perceived usefulness is a consistently strong acceptance determinant for understanding behavioural intention to adopt the technology (Venkatesh et al., 2003). Perceived usefulness is the degree to which an individual believes that using a system will improve his/her job performance (Venkatesh, 2000a; Venkatesh \& Davis, 2000). The usefulness of a system (e.g., service) is strictly related to its effectiveness (Bettiga, Lamberti, \& Lettieri, 2019), while telemedicine is a system/service. In the context of telemedicine, patients evaluate telemedicine usefulness by giving more importance to the health outcomes achieved from the services based on their expectations. In this study, perceived usefulness is the degree to which a patient believes that using telemedicine healthcare services will improve his/her mental or physical health conditions. Rho et al. (2014) acknowledged that perceived usefulness has a positive effect on behavioural intention to use telemedicine services. Similarly, in Hong Kong, perceived usefulness was a significant determinant in physicians' acceptance of telemedicine technology in hospitals (Hu et al., 1999). Consistent with prior studies, it is anticipated that when a patient's perception of telemedicine's usefulness is high, the patient is more likely to use telemedicine healthcare services. Therefore, the following hypothesis is proposed:

H2: Perceived usefulness positively influences patients' behavioural intentions to use telemedicine health services.

\subsection{Perceived Ease of Use}

Perceived ease of use refers to 'the extent to which a person believes that using the system will be free of an effort' (Venkatesh \& Davis, 2000, p. 117). In the present study, perceived ease of use is defined as the extent to how much a patient believes that using telemedicine healthcare services will be effortless. Healthcare studies using the TAM identified a significant positive effect of perceived ease of use on perceived usefulness (Dünnebeil, Sunyaev, Blohm, Leimeister, \& Krcmar, 2012). Conversely, rather than perceived ease of use, perceived usefulness has a substantial effect on behavioural intention towards telemedicine healthcare services (Aggelidis \& Chatzoglou, 2009; Hu et al., 1999) usage. This is congruent with Venkatesh (2000a), who found that perceived ease of use positively affects users' technology acceptance and intention via perceived usefulness. A recent study by Bettiga et al. (2019) confirmed that PEU has a substantial impact on predicting patients' behavioural intention in health technology adoption. Another survey by Woo and Dowding (2018) acknowledged that ease of use significantly affects patients' acceptance of telehealth services. Therefore, the following hypothesis is proposed:

H3: Perceived ease of use positively influences patients' behavioural intentions to use telemedicine health services.

\subsection{Facilitating Conditions}

Facilitating conditions refers to the 'degree to which a person believes that an organisational and technical infrastructure exists to support to use the system' (Venkatesh et al., 2003, p. 453). It incorporates three characteristics-perceived behavioural control, facilitating conditions and compatibility (Venkatesh et al., 2003) - that have a positive impact on behavioural control and behaviour (Venkatesh, Thong, \& Xu, 2012). A study by Aggelidis and Chatzoglou (2009) revealed that facilitating conditions include resources and technologies that positively affect 
ICT-supported information systems adoption. Macedo (2017), for instance, confirmed that facilitating conditions have a positive effect on behavioural intention to adopt ICT mediated services. Within the e-Health (i.e., telehealth) context, Cimperman et al. (2016) found that promoting high facilitating conditions increases behavioural intention to use telehealth services. Similarly, another recent study by Hossain, Quaresma, and Rahman (2019) asserted that facilitating conditions have positive effects on behavioural intention to use e-Health services. Therefore, the following hypothesis is proposed:

H4: Facilitating conditions positively influence patients' behavioural intentions to use telemedicine health services.

\subsection{Social Influence}

Social influence refers to the extent of how individuals behave in the way they are directly or indirectly influenced by the feelings, thoughts, and actions of others (Vries, Backbier, Kok, \& Dijkstra, 1995). Within the context of ICT, social influence can be defined as the degree to which an individual perceives that important others believe he or she should use the new system' (Venkatesh et al., 2003, p. 451) and whether others expect that individuals to execute a behaviour (Zhang et al., 2017). Another study by Lewis, Agarwal, and Sambamurthy (2003, p. 662) defines social influence as the 'perceived social pressure to perform or not to perform the particular behaviour', indicating higher perceptions of social pressure leads to a high behavioural intention to adopt technologies. For example, in the context of telemedicine, Cimperman et al. (2016) revealed that social influence strongly affects patients' behavioural intention to use telemedicine healthcare services. Macedo (2017) echoed that social influence considerably influences users' behavioural intention. Within the m-Health adoption context, Hoque, Bao, and Sorwar (2017) confirmed that social influence has a substantial impact on behavioural intention to use $\mathrm{m}$-Health services in Bangladesh. Therefore, the following hypothesis is proposed:

H5: Social influence positively influences patients' behavioural intentions to use telemedicine health services.

\subsection{Service Quality}

Service quality is defined as 'a measure of how well the service level delivered matches customer expectations' (Parasuraman, Zeithaml, \& Berry, 1985, p. 42) and is a broadly usedbut challenging (Boscarino, 1992) - healthcare service characteristic for detecting its strengths and weaknesses (Kettinger \& Lee, 1997). Service quality encompasses users' perceived service satisfaction (Kettinger \& Lee, 1997), reflecting that high quality of service contributes to high service satisfaction (K.-H. Kim, Kim, Lee, \& Kim, 2019), positive effects, and organisational accomplishment (Delone \& McLean, 2003). Zeithaml, Berry, and Parasuraman (1996) confirmed that service quality has a strong influence on customers behavioural intention. Another study by Parasuraman, Zeithaml, and Berry (1985b) revealed that most services are intangible; for example, service quality has been significantly affecting physicians' acceptance of Health Information Systems (HIS) in a hospital setting (Chen \& Hsiao, 2012), as well as users' behavioural intentions to use m-Health services (Akter, D'Ambra, \& Ray, 2010; K.-H. Kim et al., 2019). Therefore, the following hypothesis is proposed:

H6: Service quality positively influences patients' behavioural intentions to use telemedicine health services. 


\subsection{Privacy and Data Security}

Health seekers' privacy, security, and confidentiality in healthcare provision have been considered noticeable concerns that generated additional attraction in many recent empirical studies (Esmaeilzadeh, 2019). Within the e-Health context, Hall and McGraw (2014) acknowledged that there are severe privacy and data security risks in telehealth (i.e., telemedicine) services that must be addressed to succeeding in its adoption. Esmaeilzadeh (2019), for instance, revealed that prior empirical research emphasises significant shreds of evidence concerning patients' privacy violations in healthcare services, such as unauthorised access to patients' information or stolen medical data. These risks are increasing concerns in ICT mediated healthcare systems due to insufficient control over data handling (Hale \& Kvedar, 2014). Hoque et al. (2017), for example, reminded that patients might not be confident in sharing health-related information with a third party due to fear of social disgrace and discrimination. These indicate that patients are more likely to accept telemedicine healthcare services if they perceive their privacy and information are well protected. A recent study by Dutot, Bergeron, Rozhkova, and Moreau (2019) noted that secured and well-protected systems corroborate with users' attention to use healthcare services. Similarly, Xu (2019) confirmed that privacy concerns have substantial effects on patients' trust, perceived privacy and confidentiality risk, and adoption intention. Therefore, the following hypothesis is proposed:

H7: Privacy and data security positively influence patients' behavioural intentions to use telemedicine health services.

\section{Research Methodology}

\subsection{Study population}

This study has drawn from a large project, which predominantly explores the determinants of barriers, facilitators, and antecedents to health seekers' expectations of telemedicine adoption in rural public healthcare facilities in Bangladesh. A cross-sectional survey was conducted in 2017 in three Upazilas (sub-districts) telemedicine centres in Bangladesh. For this study, 500 rural patients who received telemedicine services at least once from any selected telemedicine centres in the past 12 months constitute the sampling frame. The study excluded non-users because patients in Bangladesh cannot access telemedicine services without a physician's referral.

\subsection{Data collection}

Detailed data collection procedures have been described previously (Zobair et al., 2019). The sample was drawn from selected telemedicine centres using a multistage random sampling design. At first, three districts - Pabna, Khulna and Satkhira - where telemedicine services are available were selected randomly. From these three districts, three Upazila telemedicine centres-Bera, Dacope and Devhata - were randomly selected as survey implementation site. From the patient lists collected from the selected telemedicine centres, 500 users were randomly selected, consisting of proportionate samples from Bera $(n=53)$, Dacope $(n=242)$, and Devhata $(\mathrm{n}=205)$ Upazila telemedicine centres. Each group was statistically representative of the telemedicine population with commonalities in telemedicine infrastructure and clinical methods provided by the government.

Patients' addresses and phone numbers were collected from the selected telemedicine centres. Eligible individuals were contacted by phone and invited to participate in face-to-face 
interviews at a telemedicine centre during office hours. Those unable to travel to the centres were asked to participate according to their convenience. A closed-form intervieweradministered questionnaire was used because several questions were relatively technical and would be hard for respondents with limited literacy to interpret on their own. The questionnaire was adopted in English, translated into the local language (i.e., Bengali), pretested with Bengali speakers before being administered, confirming its internal validity (Islam et al., 2015). The study met the sampling target by obtaining 500 valid responses that were scrutinised for completeness. Eight samples were excluded due to incomplete responses; 492 samples were preserved for analysis. The survey's demographics are presented in Table 1.

\begin{tabular}{|l|l|c|c|}
\hline \multicolumn{1}{|c|}{ Measure } & \multicolumn{1}{c|}{ Items } & Frequency & Percentage (\%) \\
\hline Gender & Male & 206 & 41.9 \\
\hline & Female & 286 & 58.1 \\
\hline Age & $\geq 18$ and $\leq 20$ & 64 & 13.0 \\
\hline & $\geq 21$ and $\leq 30$ & 158 & 32.1 \\
\hline & $\geq 31$ and $\leq 40$ & 106 & 21.5 \\
\hline & $\geq 41$ and $\leq 50$ & 88 & 17.9 \\
\hline Education & $\geq 51$ & 76 & 15.4 \\
\hline & Illiterate & 68 & 13.8 \\
\hline & Primary & 104 & 21.0 \\
\hline & Secondary & 178 & 36.2 \\
\hline & Higher secondary & 64 & 13.0 \\
\hline & Bachelor & 51 & 10.4 \\
\hline & Masters and above & 27 & 5.5 \\
\hline
\end{tabular}

Table 1. Demographic Characteristics of the Sample (Zobair et al., 2019)

The project received approval from the Directorate of General Health Services, Bangladesh, and Griffith University Human Research Ethics Committee. An informed consent was taken from each participant after informing them the purpose of the study, and their right to withdraw from the study at any time without consequence. They were ensured that their participation in this survey was completely voluntary.

\subsection{Construct Measurements}

A seven-point Likert scale was used (i.e., 1 = very strongly disagree to 7 = very strongly agree) for this study. A pre-test was conducted to examine the wording, sequence, length, and format of the questionnaire indicators. Fifteen individuals with expertise in telemedicine in Bangladesh were invited to pre-test the questionnaire and their feedback was used to rectify the questionnaire. The constructs, corresponding indicators and associated scales were further tested for content validity and reliability in a pilot study involving 25 telemedicine users representing $5 \%$ of the target sample (Cresswell \& Clark, 2011). The scales used in this study are drawn from prior empirical studies related to Behavioural Science, Information Technology adoption, and particularly e-Health (i.e., telemedicine) adoption research. Item scales, their corresponding measures, and adapted sources are shown in the Appendix A. These constructs were deemed significant for telemedicine research as they relate to the provision of timely responses, enhanced communication, and better access to services (Lankton \& Wilson, 2007) to secure telemedicine services sustainability in rural settings in emerging economies. 


\section{Data Analysis and Results}

This study has chosen the partial least square (PLS) approach for structural equation modeling (SEM) (Kock, 2018) instead of CB-SEM as it is a more suitable approach for many reasons (Ali, Ali, Badghish, \& Baazeem, 2018). For example, this method is a full-fledged variance-based approach ideal for the linear, non-linear, recursive, and non-recursive structural model (Benitez, Henseler, Castillo, \& Schuberth, 2020). This is a more suitable choice for explorative studies and highly complex casual (i.e., confirmatory and explanatory) models (Otter \& Beer, 2021). PLS-SEM has distinctive features that do not follow the restrictive assumptions imposed by CB-SEM (Ali et al., 2018; Astrachan, Patel, \& Wanzenried, 2014). Compared to CB$\mathrm{SEM}$, it is a more robust approach with fewer identification issues and works with smaller and larger sample sizes (Hair, Ringle, \& Sarstedt, 2011). PLS-SEM can more effectively provide parameter estimates than CB-SEM under appropriate circumstances (Hair Jr, Hult, Ringle, \& Sarstedt, 2016). For instance, Hair, Ringle, and Sarstedt (2013) noted that the PLS-SEM representation of graphical model structures renders the model under investigation easier to manage and comprehend, allowing for rapid reconfigurations and real-time feedback.

Further, PLS-SEM can easily manage both reflective and formative measurement models (Hair et al., 2011), including a single-item construct (Hair Jr et al., 2016). In contrast, model estimation with many latent constructs or indicators is often impossible with CB-SEM (Hair Jr, Hult, Ringle, \& Sarstedt, 2017). PLS-SEM uses latent constructs scores as an exact linear combination of the observed indirect constructs (Schubring, Lorscheid, Meyer, \& Ringle, 2016) and is more suited for theory building and predictive applications (Gefen, Straub, \& Boudreau, 2000). Compared to CB-SEM results, which can be highly imprecise when the assumptions are violated, PLS-SEM provides more robust estimations of the structural model (Hair et al., 2011). Besides, PLS-SEM has greater statistical power than CB-SEM (Hair et al., 2011). Finally, the PLS-SEM method provides more robust estimations of the structural model and has greater statistical power than CB-SEM (Hair et al., 2011).

This study's model contains a single endogenous (i.e., dependent) latent construct $(Z / \eta$ denotes $\mathrm{BI}$ ) and seven exogenous (i.e., independent) latent constructs (SI), (FC), (PEU), (PU), (SE), (PDS) and (SQ), which are indicated as ovals (Hair et al., 2011). Chin (1998) suggested that PLS design assumes recursive (i.e., one way arrowed) relations among latent constructs and each endogenous latent construct $\eta$ often termed casual chain systems of latent constructs that can be specified by equation 1 . The mathematical equation of the structural model of this study is shown in equation 1.

$$
\eta=\Sigma \beta_{1} \xi_{1}+\Sigma \beta_{2} \xi_{2}+\Sigma \beta_{3} \xi_{3}+\Sigma \beta_{4} \xi_{4}+\Sigma \beta_{5} \xi_{5}+\Sigma \beta_{6} \xi_{6}+\Sigma \beta_{7} \xi_{7}+\delta . \quad[1]
$$

where $\eta$ is an endogenous latent construct, $\beta$ is a path coefficient, and $\xi 1$ is an exogenous latent construct. Literature indicates that all variance-based SEM detects a nonzero path coefficient; however, the effect is originally zero (Dijkstra \& Henseler, 2015). Therefore, the mathematical equation of this model is yielding the following regression equation:

$$
\mathrm{Z}=+\beta_{1} \mathrm{SI}+\beta_{2} \mathrm{FC}+\beta_{3} \mathrm{PEU}+\beta_{4} \mathrm{PU}+\beta_{5} \mathrm{SE}+\beta_{6} \mathrm{PDS}+\beta_{7} \mathrm{SQ}+\mathrm{e} .[2]
$$

Eq 2 charactierises the extended technology acceptance model process, where $Z$ is the outcome (behavioural intention) of social influence $(S I)$, facilitating conditions $(F C)$, perceived ease of use $(P E U)$, perceived usefulness $(P U)$, self-efficacy $(S E)$, privacy and data security $(P D S)$, and service quality $(S Q)$ latent constructs. All partial regression models are estimated iteratively (PLS-SEM algorithm) in two stages (Hair et al., 2011). In the first stage, construct scores are 
estimated. Then in the second stage, final estimates of the outer weights and loadings are calculated, with the structural model's path coefficients and the resulting $\mathrm{R}^{2}$ values of the endogenous latent construct (Hair Jr et al., 2017).

The dataset was analysed using PLS-SEM (Muthupoltotage \& Gardner, 2018) largely consisting of latent constructs that require measurement by a set of indicators as proxies (Hair Jr et al., 2017). It incorporates two sets of linear equations - a measurement model specifying a construct and its corresponding indicators and a structural model specifying the relationship between exogenous and endogenous constructs and addressing the research questions and hypotheses (Henseler, Hubona, \& Ray, 2017). Therefore, the PLS-SEM technique is considered a more rigorous analysis for the proposed research model (Muthupoltotage \& Gardner, 2018). SmartPLS v.3.2.8 was utilized for data analysis, the PLS (algorithm) tool for testing scales reliability, and a bootstrapping (algorithm) technique for hypotheses and structural model testing.

\subsection{Measurement Model}

This research evaluates the reliability and validity of the reflective measurement model constructs (Ringle, Sarstedt, \& Straub, 2012) without choosing a composite model. A recent study by Benitez et al. (2020) revealed that a reflective and casual-formative model is usually used for behavioural studies since a composite model is employed for artefacts. However, PLS-SEM deals with both latent variables (i.e., a construct that represents a behavioural concept such as individual behaviour, attitude, and personality traits) and emergent variables (i.e., a construct that represents an artifact) (Benitez et al., 2020). In PLS-SEM, a composite model can be estimated by Mod B; in turn, a reflective measurement model should be evaluated by Mod A (Benitez et al., 2020). The reason for choosing a reflective measurement model for this research is that the evaluation of Mod A relies on a different set of criteria than its composite counterparts Mod B (Benitez et al., 2020).

The measurement model was evaluated by testing internal consistency reliability, indicator reliability, convergent validity, and discriminant validity (Hair et al., 2017). All outer loadings for each indicator in the model (see Table 2) were higher than the threshold value of 0.707 , suggesting that more than $50 \%$ of the variance in a single indicator can be explained by the corresponding latent construct, confirming indicator reliability (Benitez et al., 2020; Hair et al., 2017; Roldán \& Sánchez-Franco, 2012). Our results show (see Table 2) that the loadings range from 0.711 to 0.821 , and all are significant on a $1 \%$ level, authenticating that the measures are reliable (Benitez et al., 2020).

Both Cronbach's alpha and composite reliability $>0.707$ (see Table 2) confirmed the model's statistical significance and demonstrated strong evidence of internal consistency reliability (Hair et al., 2017; Roldán \& Sánchez-Franco, 2012). The Cronbach's alpha and composite reliability range from 0.849 to 0.727 and 0.889 to 0.841 , respectively, are above the threshold value, demonstrating reliable construct scores (Benitez et al., 2020). Convergent validity ( $\geq .50)$ was assessed using the average variance extracted (AVE) values for each construct (see Table 2) (Hair et al., 2017). AVE values in our model range for 0.647 to 0.554 are higher than the threshold value of $>.50$, indicating significant convergent validity (Benitez et al., 2020; Henseler et al., 2017). The AVE values for each construct explain the variance of more than half of their corresponding indicators, confirming convergent validity (Henseler, Ringle, \& Sinkovics, 2009; Roldán \& Sánchez-Franco, 2012). 


\begin{tabular}{|c|c|c|c|c|c|c|c|}
\hline Latent Construct & $\begin{array}{l}\text { Indicator } \\
\text { Code }\end{array}$ & Loading & AVE & $\begin{array}{l}\text { Cronbach's } \\
\text { Alpha }\end{array}$ & $\begin{array}{l}\text { Composite } \\
\text { Reliability }\end{array}$ & $R^{2}$ & $R^{2} A d j$ \\
\hline \multirow[t]{4}{*}{$\begin{array}{l}\text { Behavioural intention to } \\
\text { use TM }\end{array}$} & BI1 & $0.767^{* * *}$ & 0.579 & 0.757 & 0.846 & 0.655 & 0.650 \\
\hline & BI2 & $0.755^{* * *}$ & & & & & \\
\hline & BI3 & $0.800^{* * *}$ & & & & & \\
\hline & BI4 & $0.727^{* * *}$ & & & & & \\
\hline \multirow[t]{6}{*}{ Facilitating conditions } & FC1 & $0.744^{* * *}$ & 0.554 & 0.839 & 0.882 & & \\
\hline & FC2 & $0.722^{* * *}$ & & & & & \\
\hline & FC3 & $0.755^{* * *}$ & & & & & \\
\hline & FC4 & $0.762^{* * *}$ & & & & & \\
\hline & FC5 & $0.726^{* * *}$ & & & & & \\
\hline & FC6 & $0.756^{* * *}$ & & & & & \\
\hline \multirow[t]{3}{*}{ Privacy and data security } & PDS1 & $0.796^{* * *}$ & 0.647 & 0.727 & 0.846 & & \\
\hline & PDS2 & $0.805^{* * *}$ & & & & & \\
\hline & PDS3 & $0.812^{* * *}$ & & & & & \\
\hline \multirow[t]{4}{*}{ Perceived ease of use } & PEU1 & $0.795^{* * *}$ & 0.570 & 0.747 & 0.841 & & \\
\hline & PEU2 & $0.720^{* * *}$ & & & & & \\
\hline & PEU3 & $0.790^{* * *}$ & & & & & \\
\hline & PEU4 & $0.711^{* * *}$ & & & & & \\
\hline \multirow[t]{4}{*}{ Perceived usefulness } & PU1 & $0.771^{* * *}$ & 0.612 & 0.788 & 0.863 & & \\
\hline & PU2 & $0.774^{* * *}$ & & & & & \\
\hline & PU3 & $0.818^{* * *}$ & & & & & \\
\hline & PU4 & $0.765^{* * *}$ & & & & & \\
\hline \multirow[t]{4}{*}{ Self-efficacy } & SE1 & $0.757^{* * *}$ & 0.588 & 0.767 & 0.851 & & \\
\hline & SE2 & $0.757^{* * *}$ & & & & & \\
\hline & SE3 & $0.752^{* * *}$ & & & & & \\
\hline & SE4 & $0.801^{* * *}$ & & & & & \\
\hline \multirow[t]{5}{*}{ Social influence } & SI1 & $0.730^{* * * *}$ & 0.604 & 0.835 & 0.884 & & \\
\hline & SI2 & $0.729^{* * *}$ & & & & & \\
\hline & SI3 & $0.787^{* * *}$ & & & & & \\
\hline & SI4 & $0.821^{* * *}$ & & & & & \\
\hline & SI5 & $0.813^{* * *}$ & & & & & \\
\hline \multirow[t]{6}{*}{ Service quality } & SQ1 & $0.776^{* * *}$ & 0.571 & 0.849 & 0.889 & & \\
\hline & SQ2 & $0.741^{* * *}$ & & & & & \\
\hline & SQ3 & $0.758^{* * * *}$ & & & & & \\
\hline & SQ4 & $0.741^{* * *}$ & & & & & \\
\hline & SQ5 & $0.790^{* * *}$ & & & & & \\
\hline & SQ6 & $0.726^{* * *}$ & & & & & \\
\hline
\end{tabular}

Table 2. Measurement Model Assessment

Note: $t p<0.10,{ }^{*} p<0.05,{ }^{* *} p<0.01,{ }^{* * *} p<0.001$, one-tailed test. 
Discriminant validity defines the extent to which a construct in a model is distinct from other constructs by empirical standards (Henseler et al., 2009). A construct accepts more variance from its assigned items than from any other constructs (Henseler et al., 2009). This study measured the distinctiveness of a latent construct using the heterotrait-monotrait ratio (HTMT) criterion test. Literature indicates that the HTMT criterion is essential to evaluate the constructs' discriminant validity (Benitez et al., 2020; Hair Jr, Howard, \& Nitzl, 2020; Otter \& Beer, 2021). The cut-off scores should be smaller than 0.85 or 0.90 to interpret the results (Benitez et al., 2020; Hair Jr et al., 2020). The results (see Table 3) demonstrate that HTMT is significantly less than 0.85 or 0.90 , authenticating that all measured constructs illustrated their discriminant validity (Benitez et al., 2020) except two pairs. Our results provided evidence that we established discriminant validity among all constructs. However, we cannot confirm discriminant validity between two pairs of constructs such as PDS and BI, and PEU and PU contain the HTMT value of 0.937 and 0.981 , respectively, suggesting a lack of discriminant validity.

\begin{tabular}{|l|c|c|c|c|c|c|c|c|}
\hline & BI & FC & PDS & PEU & PU & SE & SI & SQ \\
\hline BI & & & & & & & & \\
\hline FC & 0.846 & & & & & & & \\
\hline PDS & 0.937 & 0.842 & & & & & & \\
\hline PEU & 0.868 & 0.820 & 0.859 & & & & & \\
\hline PU & 0.872 & 0.833 & 0.872 & 0.981 & & & & \\
\hline SE & 0.686 & 0.754 & 0.670 & 0.802 & 0.735 & & & \\
\hline SI & 0.796 & 0.877 & 0.665 & 0.829 & 0.693 & 0.814 & & \\
\hline SQ & 0.890 & 0.779 & 0.871 & 0.838 & 0.838 & 0.748 & 0.716 & \\
\hline
\end{tabular}

Table 3. Heterotrait-Monotrait Ratio (HTMT) for Discriminant Validity

Note: $\mathrm{BI}=$ behavioural intention to use telemedicine; FC = facilitating conditions; PDS = privacy and data security; $\mathrm{PEU}=$ perceived ease of use; $\mathrm{PU}$ = perceived usefulness; $\mathrm{SE}=$ self-efficacy; $\mathrm{SQ}$ = service quality; SI = social influence.

Further, the bootstrapping technique applied for testing whether the HTMT value is significantly less than 1 (Hair Jr et al., 2017). Our results demonstrated that HTMT is considerably less than 1 (Benitez et al., 2020). We found that neither of the confidence intervals includes the value 1 (Hair Jr et al., 2017) except PDS and BI, PU and PEU, similar to the previous test. Our results show that the lower and upper bounds of the confidence interval of HTMT for the relationships between PDS and BI are 0.860 and 1.011, PU and PEU are 0.921 and 1.037, indicating that these constructs in the path model are more distinct, suggesting a lack of discriminant validity (Hair Jr et al., 2017). Except these, the bootstrap confidence interval results of the HTMT criterion support the construct's acceptable discriminant validity (Hair Jr et al., 2017). These results are unexpected and need further investigation.

\subsection{Structural Model}

The structural model was developed to describe the relationships among the latent constructs and examine their significance (Roldán \& Sánchez-Franco, 2012). A bootstrapping technique using 5,000 iterations tested the statistical significance of the relationships between endogenous and exogenous latent constructs in the structural path models (Hair Jr et al., 2017). The structural model and hypothesised relationships between constructs were tested using a standardised path coefficient $(\beta)$ and t-statistics (see Tables 2 and 4 ) at $p<0.05, p<0.01$ and 
$p<0.001$ (Benitez et al., 2020). However, a consistent PLS (PLSc) version was developed to correct the bias and consistently estimate SEMs with common factors (Schuberth, Henseler, \& Dijkstra, 2018). These enhancements are based on the PLS algorithm and, thus, on ordinary least squares (OLS) regression analysis, implicitly assuming that all indicators are continuous (Schuberth et al., 2018). The reason for choosing the PLS algorithm for this research is that previous health adoption studies, for example, (Chang et al., 2015; Hoque et al., 2017; Hoque \& Sorwar, 2017; Hsia, Chiang, Wu, Teng, \& Rubin, 2019; Lankton \& Wilson, 2007; Zobair et al., 2019) have widely used the PLS algorithm and associated bootstrapping procedure to examine the statistical significance and test hypotheses.

The structural model revealed that 5 hypotheses were supported by the relationships $\mathrm{p}<0.05$, $p<0.01$ and $p<0.001$ (see Table 4 and Figure 3). The five proposed latent constructs had significant effects (see Tables 2 and 4) on behavioural intention (BI) to use telemedicine healthcare services. The findings show that the relationships between service quality (SQ) and BI $(\beta=0.258, t=4.015, p<0.001)$, privacy and data security (PDS) and BI $(\beta=0.249, t=4.232$, $p<0.001)$, social influence (SI) and BI $(\beta=0.193, t=3.650, p<0.001)$, perceived usefulness (PU) and BI $(\beta=0.148, t=2.478, p<0.01)$ and facilitating conditions (FC) and BI $(\beta=0.102, t=1.691, p<0.05)$ were statistically significant, confirming support for $\mathrm{H} 6, \mathrm{H} 7, \mathrm{H} 5, \mathrm{H} 2$ and $\mathrm{H} 4$ (one-tailed test, see Table 4 ) respectively. An $\mathrm{R}^{2} \approx 0.65$ indicates that about $65 \%$ of the variance (i.e., $\mathrm{BI}$ ) in the model was jointly explained by SQ, PDS, SI, PU and FC. The results were close to a substantial R2 value (i.e., 67\%) (Henseler et al., 2009), suggesting high predictive capability of the model. Further, $\mathrm{R}^{2}$ demonstrates each construct's significance and its associative contribution to overall $R^{2}$ (Wilson, 2010). Therefore, the findings (see Figure 3) confirm that service quality, privacy and data security, social influence, usefulness and facilitating conditions substantially impact patients' behavioural intention towards telemedicine health services adoption in rural Bangladesh's public hospital settings.

\begin{tabular}{|c|c|c|c|c|c|c|}
\hline \multicolumn{2}{|c|}{ Hypotheses } & Path Coefficient $(\beta)$ & SE & $t$ & $p$ & Decision \\
\hline H1 & SE $\rightarrow$ BI & -0.065 & 0.043 & 1.521 & 0.064 & Unsupported \\
\hline H2 & PU $\rightarrow$ BI & $0.148^{* *}$ & 0.060 & 2.478 & 0.007 & Supported \\
\hline H3 & PEU $\rightarrow$ BI & 0.060 & 0.066 & 0.918 & 0.173 & Unsupported \\
\hline H4 & FC $\rightarrow$ BI & $0.102^{*}$ & 0.060 & 1.691 & 0.045 & Supported \\
\hline H5 & SI $\rightarrow$ BI & $0.193^{* * *}$ & 0.053 & 3.650 & 0.000 & Supported \\
\hline H6 & SQ $\rightarrow$ BI & $0.258^{* * *}$ & 0.064 & 4.015 & 0.000 & Supported \\
\hline H7 & PDS $\rightarrow$ BI & $0.249^{* * *}$ & 0.059 & 4.232 & 0.000 & Supported \\
\hline
\end{tabular}

Table 4. Structural Model Assessment

Note: $+p<0.10,{ }^{*} p<0.05,{ }^{* *} p<0.01,{ }^{* * *} p<0.001$, one-tailed test.

The structural model further revealed that two other hypotheses were not supported. The relationships between SE and BI $(\beta=-0.065, t=1.521, p<0.05)$, PEU and BI $(\beta=0.060, t=0.918$, $p<0.05$ ), were statistically not significant. This invalidates $\mathrm{H} 1$ and $\mathrm{H} 3$ (see Table 4), indicating that SE, BI, and PEU and BI do not contribute to patients' acceptance and behavioural intention towards adopting telemedicine health services in rural Bangladesh's public hospital settings. 


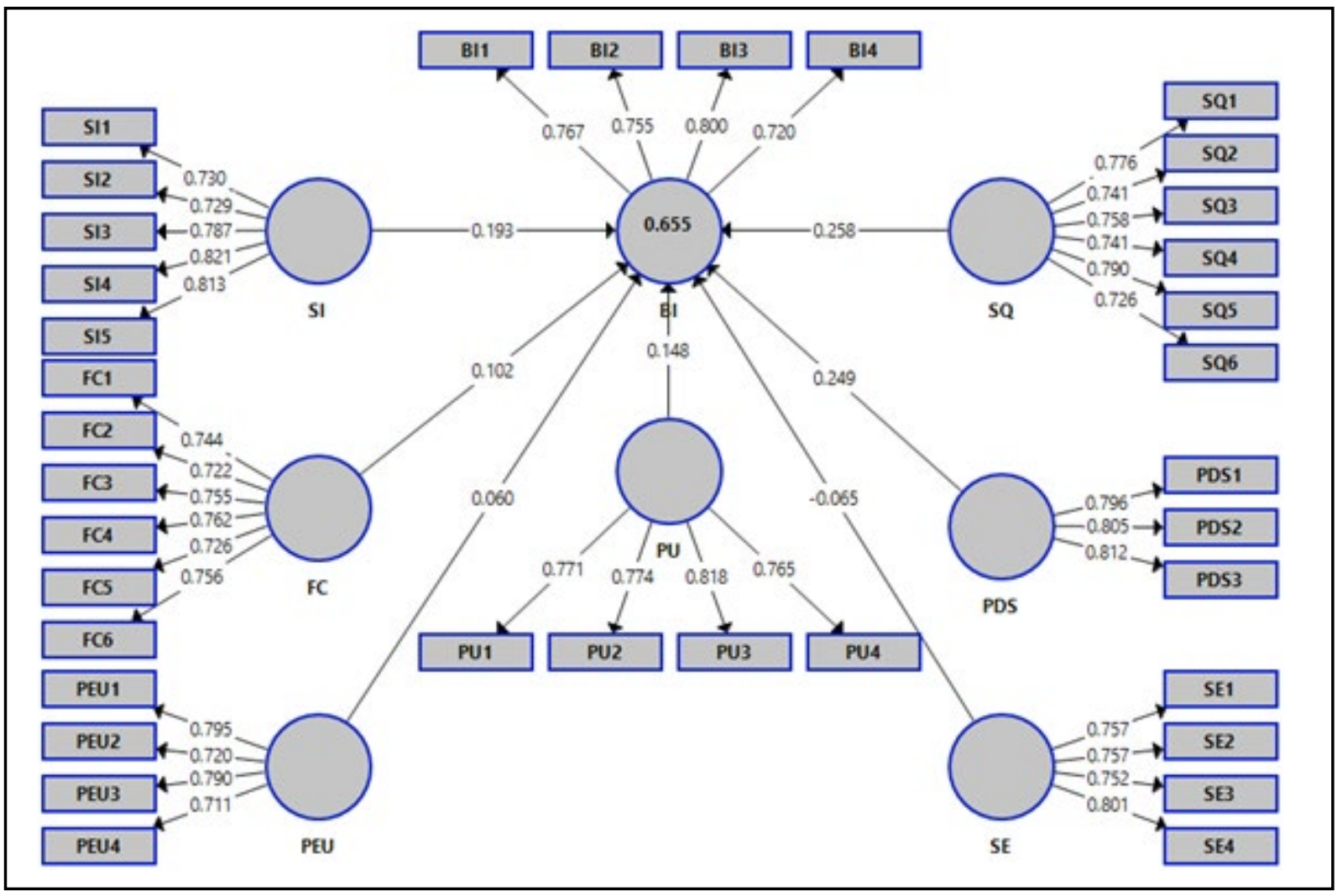

Figure 2. Final PLS-SEM structural model for acceptance and adoption of telemedicine healthcare services

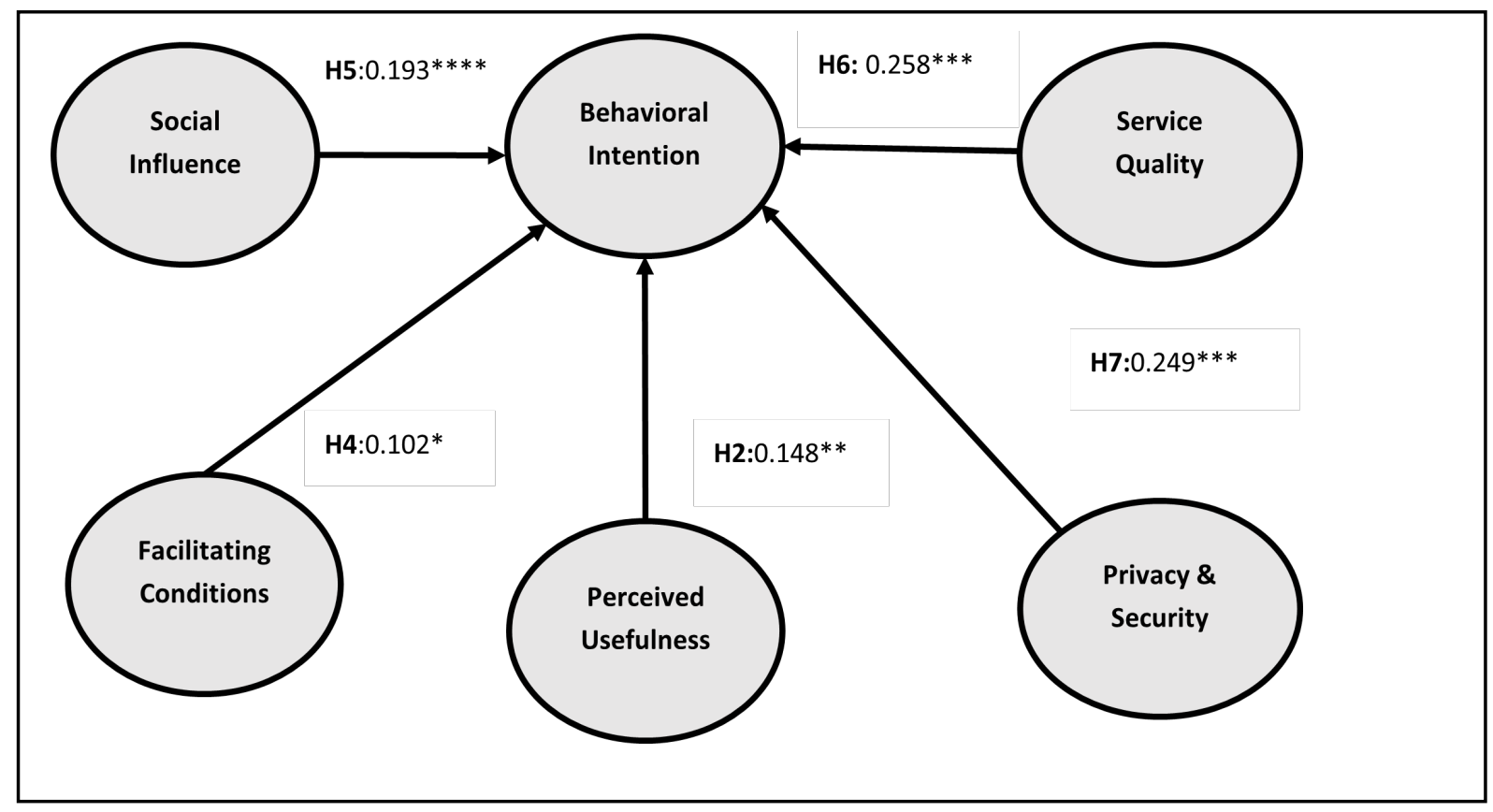

Figure 3. Final model with confirmed Hypotheses.

Note: $t p<0.10 ;{ }^{*} p<0.05 ;{ }^{* *} p<0.01 ;{ }^{* * *} p<0.001$ one tailed test.

Due to recent PLS-SEM developments, the overall model fit can be estimated using standardised root mean squared residual (SRMR), squared Euclidean distance, and the geodesic distance (Hair Jr et al., 2020). The measure of fit (SRMR) and the test of overall model 
fit squared Euclidian distance (duss) and the geodesic distance $\left(\mathrm{d}_{\mathrm{G}}\right)$ is preferable in casual research (Benitez et al., 2020; Hair Jr et al., 2020). The discrepancy between the two matrices is measured by squared duss, dG, and the SRMR (Benitez et al., 2020; Hair Jr et al., 2020) assuming, the significance at $5 \%$ (Benitez et al., 2020). The recommended threshold value of SRMR should be below 0.080, and all discrepancy measures should be below the (duss and $\mathrm{d}_{\mathrm{G}}$ ) $95 \%$ quantile of their reference distribution (HI95) (Benitez et al., 2020). In our model (see Table 5), all values of discrepancy are below the $95 \%$ quantile of their corresponding reference distribution ( $\left.\mathrm{HI}_{95}\right)$ except (durs), authenticating acceptable overall model fit. Further, the SRMR is below the threshold value of 0.080, indicating a good model fit (Benitez et al., 2020). However, the squared Euclidean distance in this model is significantly high, and more investigations are encouraged on this new enhancement/development.

\begin{tabular}{|l|l|l|l|}
\hline Discrepancy & Value & HI95 & Decision \\
\hline SRMR & 0.058 & 0.045 & Supported \\
\hline duts & 2.230 & 1.332 & Unsupported \\
\hline $\mathrm{d}_{\mathrm{G}}$ & 0.836 & 0.587 & supported \\
\hline
\end{tabular}

Table 5. Overall Saturated Model Fit Evaluation

\section{Discussion}

This is the first known inclusive study in Bangladesh (utilising the extended version of TAM) that explicitly investigated determinants of health seekers' behavioural intentions to accept and adopt telemedicine in the rural public healthcare setting. Even though a significant body of studies have explored patients' behavioural intentions to telemedicine adoption in highand middle-income countries (Aggelidis \& Chatzoglou, 2009; Hoque \& Sorwar, 2017; Leung \& Chen, 2019; Maillet, Mathieu, \& Sicotte, 2015), the present study contributes to the health informatics literature by demonstrating determinants of telemedicine adoption predominately in rural healthcare facilities of a low-income country. Consistent with previous studies (Hoque \& Sorwar, 2017; Leung \& Chen, 2019; Maillet et al., 2015), findings from this study reveal that perceived usefulness, facilitating conditions, social influence, service quality, and privacy and data security are five leading determinants prompting patients' acceptance behaviours towards telemedicine adoption.

This study showed that SQ had the most significant effect on patients' behavioural intentions (H6) to accept telemedicine healthcare services in rural Bangladesh settings. Evidence suggests that service quality is a strong determinant of patients' telemedicine acceptance in developing countries settings (Ivatury, Moore, \& Bloch, 2009). Within the m-Health context, Akter et al. (2010) found strong relationships between service quality and patients' satisfaction. Davis et al. (2019), for example, found $89 \%$ of patients were satisfied with the service quality via teleneurology services. This indicates that telemedicine services quality has a strong effect on patients' behavioural intention (Cronin Jr, Brady, \& Hult, 2000) and subsequent acceptance and adoption of telemedicine healthcare services. Within the healthcare context, service quality can be measured by evaluating patients' health expectations against actual service performance (Parasuraman et al., 1985).

Health seekers' satisfaction is critically important to determine whether patients continue to experience these services or move to different providers (Hill \& Doddato, 2002). Satisfied patients will most likely return to a service (i.e., behavioural intention to use) and share their encouraging experiences through word-of-mouth with others (Cronin Jr et al., 2000; Hill \& 
Doddato, 2002). For example, service quality significantly affected patients' behavioural intentions to use m-Health services (Akter et al., 2010) and physicians' acceptance of HIS (Chen \& Hsiao, 2012). Within m-Health services, a recent study by K.-H. Kim et al. (2019) found that users' service satisfaction has the most significant effect on the continuity of intention to use m-Health services. Today's health seekers expect high service quality from their health providers through continuous, round-the-clock health access, immediate appointments, lengthy consultations, and reduced wait times (Yarbrough \& Smith, 2007).

Applied to an IS success context, Delone and McLean (2003) suggest that service quality is considered to be the most crucial variable. Our findings are consistent with prior studies. This study argues that service quality to serve as determinants of patients' behavioural intentions to accept and adopt telemedicine is reflected in the current rural telemedicine service phenomenon. This is because, the rural patients are characterised geographically isolated, and telemedicine care by a specialist through videoconferencing is comparable to face to face specialised care benefiting their health and wellbeing without travelling for hospitalised treatment (Ferrer-Roca, Garcia-Nogales, \& Pelaez, 2010). Our findings provide strong evidence of rural patients' being influenced by telemedicine service quality, indicating improved service quality in telemedicine is more likely to lower health seekers' anxiety levels and improve their behavioural intentions to use telemedicine services. Therefore, service quality presents a significant determinant in predicting patients' behavioural intentions to accept and adopt telemedicine healthcare services in rural Bangladesh.

Similar to the findings of prior studies (Kim \& Park, 2012; Or et al., 2011; Venkatesh \& Bala, 2008; Venkatesh et al., 2003; Wu, Shen, Lin, Greenes, \& Bates, 2008), results from this study demonstrated that PU had a significant effect on behavioural intention to accept and adopt telemedicine healthcare services, as it supports H2. Similar to the study by Venkatesh and Davis (2000), perceived usefulness is a strong determinant of patients' behavioural intentions, explaining telemedicine adoption intentions in rural Bangladesh's public hospital settings. A recent study by Leung and Chen (2019) demonstrated that PU has significantly contributed to patients' continuous intentions to use e-Health services (i.e., telemedicine). This finding shows that PU is a strong predictor of patients' acceptance towards telemedicine adoption intentions indicating that patients intend to use telemedicine when they perceive it is useful for addressing their disease concerns, wants and needs. This is consistent with a prior study by Davis (1989) which revealed that people intend to use or not to use a service (i.e., application) depending on whether it will exceed their expectations. For example, Aggelidis and Chatzoglou (2009) studied extended TAM and found that PU has a substantial effect on the behavioural intentions of health staff to accept and adopt HIS.

Another recent study by Koceska et al. (2019) found that PU has a substantial effect on behavioural intention to use mobile health monitoring systems. Within the m-Health context, Zhang et al. (2017) found that PU is a significant determinant of the adoption intention of mHealth services. In the context of e-Health, Hoque et al. (2017) confirmed that PU has substantial impacts on predicting users' intention to use e-Health services. Our findings are consistent with existing literature, authenticating that the PU construct is a significant determinant of predicting patients' behavioural intentions to accept and adopt telemedicine services.

This study reveals the PDS construct had substantial effects on patients' behavioural intentions to accept and adopt telemedicine healthcare services, supporting $\mathrm{H} 7$ and indicating that rural 
patients desire that health providers keep protected their health status and data. This result comports with other studies showing that privacy, and data security (PDS) issues have a dominating effect on users' behavioural intentions of accepting and adopting telemedicine healthcare services (Akter et al., 2010; Zhou et al., 2019). A study revealed that health-seeking behaviour is strongly influenced by privacy-related concerns in healthcare services (Cheng, Savageau, Sattler, \& DeWitt, 1993). Patients expect privacy and confidentiality. This is supported by Kamal, Shafiq, and Kakria (2020) acknowledged that privacy and data security significantly contributed to adopting telemedicine services in developing countries. Our results validate that the PDS construct is a strong determinant in predicting behavioural intention to accept and adopt telemedicine, highlighting that health providers must keep patients' health information confidential and secure to ensure continued acceptance of telemedicine. Our results are consistent with prior empirical studies and are informative and relevant.

The significance of our findings associated with PDS is further highlighted. For example, some empirical evidence indicates that health-seeking behaviour is strongly influenced by privacyrelated issues in healthcare services (Cheng et al., 1993), while Wilkowska and Ziefle (2011) acknowledged that privacy and confidentiality have substantial effects on users' health technology acceptance. Chang (2015) pointed out that a lack of security, privacy and confidentiality is potentially significant in the acceptance and adoption of health technology, as telemedicine involves the electronic transmission and storage of patient health-related data. The risk of privacy and data security breaches can arise in healthcare systems due to insufficient control over data handling (Hale \& Kvedar, 2014). This is supported by Kamal et al. (2020) acknowledged that privacy and data security significantly contributed to adopting telemedicine services in developing countries. Our results validate that the PDS construct is a strong determinant in predicting behavioural intention to accept and adopt telemedicine, highlighting that health providers must keep patients' health information confidential and secure to ensure continued acceptance of telemedicine. Our results are consistent with prior empirical studies and are informative and relevant.

Findings from this study suggest that SI plays a significant role in rural patients' behavioural intentions to use telemedicine healthcare services in Bangladesh, supporting H5. Patients' telemedicine acceptance decisions could be strongly influenced by their family members, friends, physicians, social media, and legislative awareness. This finding is consistent with previous literature. For example, studies confirmed that social influence is a significant determinant influencing users' behavioural intentions to accept and adopt health technologies (Karahanna \& Straub, 1999), such as m-Health services (Hoque et al., 2017) and wireless-based mobile services (Lu, Yao, \& Yu, 2005). This indicates that higher perceived social pressure is more likely to heighten behavioural intention to accept and adopt technologies. More precisely, with health context, Cimperman et al. (2016) indicate that positive social influence and support strongly affect patients' behavioural intentions to use healthcare systems. Alam et al. (2020) further acknowledged that social influence significantly impacts the behavioural intention to accept and adopt $\mathrm{m}$-Health services in Bangladesh. Our findings have suggested that social influence is an essential determinant in predicting health seekers acceptance and adoption of telemedicine in rural hospital settings.

Consistent with prior studies, this study reveals that the facilitating conditions construct has the dominating effects on patients' behavioural intentions of telemedicine services adoption, 
supporting H4. This result comports with other studies showing that the facilitating conditions significantly influence the users' behavioural intentions (Jewer, 2018; Venkatesh et al., 2003). Likewise, Alam et al. (2020) found that facilitating conditions contributed to patients' behavioural intentions of adopting $\mathrm{m}$-Health services in Bangladesh. A recent study by Dutot et al. (2019) asserted that facilitating conditions have positive effects on users' behavioural intentions to use systems/services. Within the e-Health context, Hossain et al. (2019), for example, revealed that facilitating conditions have a significant impact on behavioural intention to use e-Health (i.e., telemedicine) services. These findings are consistent with Venkatesh et al. (2012), who confirmed a solid link between social influence and users' behavioural intentions to use technology. Our results suggest that the facilitating conditions construct remains a strong determinant, potentially predicting health seekers' behavioural intentions to accept and adopt telemedicine healthcare services in rural Bangladesh.

Additionally, this study confirmed that the SE and PEU had no direct effects on the BI in the proposed model ( $\mathrm{H} 1$ and $\mathrm{H} 3$ are not supported). These results underscore the importance of the impact on patients' behavioural intentions. However, these findings are consistent with prior studies as PEU construct (Or et al., 2011) and SE constructs (Maillet et al., 2015) unable to make any significant contributions to predict users' behavioural intentions of adopting telemedicine healthcare services. Interestingly, Kim and Park (2012) acknowledged that selfefficacy and ease of use had significant effects on the behavioural intention of HIT. This study argues that the inability of self-efficacy and ease of use to serve as determinants of patients' behavioural intentions to accept and adopt telemedicine is reflected in the current rural telemedicine service phenomenon. The study findings may be unexpected, but it may indicate that in Bangladesh, telemedicine healthcare services and technical, operational, and administrative support is actively managed by its ICT staff and physicians. Patients remain passive and lack control over those issues. These findings are consistent with current telemedicine operations and critical management criteria that have been empirically proven, indicating that patients may have minimal interaction with the technology during consultation.

\subsection{Contributions and Implications}

The present study contributes to theory-based testing models (i.e., the TAM and SCT) to examine the determinants of acceptance and antecedents of expectation associated with telemedicine adoption. Prior studies have drawn on many behavioural theories, including the TAM (Agarwal, Sambamurthy, \& Stair, 2000), to better understand users' acceptance or rejection of technologies (Davis, 1989; Davis et al., 1989). In the context of health, social learning theory, SE, and locus of control have been applied for understanding, explaining, predicting, and influencing behaviour (Rosenstock et al., 1988). The present study built on these previous studies, for instance (Bandura, 1977, 1986; Davis et al., 1989; Shankar, Smith, \& Rangaswamy, 2003; Venkatesh, 2000a; Venkatesh \& Davis, 1996), integrated their theories and uniquely applied the TAM and SCT to identify and examine rural patients' acceptance and expectations of telemedicine adoption in emerging economies' public hospital settings.

This study's findings have important implications for information systems, particularly in health informatics research from a managerial perspective. The extended TAM model appears sound and could become a benchmark model to study patients' acceptance and future service continuity in the telemedicine domain. This suggests that health providers should enhance patients' happiness to keep secure patients' long-term service acceptance and continuity with 
telemedicine. Secondly, this study employed an extended TAM framework to significantly contribute to predict, understand and explain health seekers' behavioural intention to accept and adopt telemedicine health services in rural settings in a developing country's context. Thirdly, determinants that influence health seekers' behavioural choices to use telemedicine in the context of rural areas in a developing country are explored and noted. Generally, rural and urban patients' intentions to adopt telemedicine services are disparate due to differences in their social, cultural, and facilitating circumstances. Fourthly, the results provide government, policymakers, implementers, and stakeholders with a clear picture of telemedicine projects' causative factors, adoption successes and failures. Finally, it identifies five exemplary determinants to patients' telemedicine acceptance and adoption -SQ, PU, FC, SI and PDS - that merit further policy intervention for the successful adoption of telemedicine services in rural settings, including healthcare industry improvement in Bangladesh and similar settings.

From telemedicine implementation and actual uses standpoints, our findings point to the importance of providing a high quality of care, protecting patients' privacy, prompt responsiveness and health outcomes, ensure well-facilitating service conditions. The health providers additional support build patients' trust that plays a significant role in a positive attitude towards new technology-mediated telemedicine acceptance and future continuity.

\subsection{Research impact}

The present study's underlying impacts are classified into seven-dimensional categories: knowledge, stakeholders, theory, situational, model, country, and data collection. This study's knowledge contributed to defining, distinguishing, explaining, interpreting, and predicting telemedicine adoption determinants in contexts like emerging economies' rural settings. It provides unique insights into rural patients' (stakeholders') views regarding telemedicine services. Further, this research identified four areas of impact, namely (1) research related (i.e., research problem, methods used, research management and communication), (2) policy (i.e., level of policymaking, type, nature and policy networks), (3) service (i.e., health services, service management, quality of care, and information systems) and (4) social-based (i.e., attitudes behaviour, health literacy, health status, and sustainable health outcomes) on research impact framework (Kuruvilla, Mays, Pleasant, \& Walt, 2006). Failure to recognise these determinants and impacts stakeholders' acceptance and expectations of telemedicine will undermine attempts to implement in emerging economies.

\subsection{Limitations and future Research}

TAM model has successfully predicted user technology acceptance and usage continuance (Ramkumar, Schoenherr, Wagner, \& Jenamani, 2019). However, using TAM without extending it might not explain how users accept a new technology (Alshammari \& Rosli, 2020). The designed goal of the present research involves extending the TAM model. Not surprisingly, the contemporary IS research literature has become choked and confused by various TAM extensions and TAM verifications in varied contexts. Consequently, authors of such research reports face a challenging hurdle in making a case for the need (motive), the novelty, and the significance of findings that extend the TAM model or its operation in different contexts, demonstrating one of the significant theoretical limitations.

Evidence suggests that contemporary healthcare services are becoming heavily reliant on technology (Jewer, 2018); thus, thoughtful research on users' acceptance concerning 
technology-mediated healthcare services (i.e., telemedicine) is now crucial for sustaining this provision. However, TAM's significant weaknesses/limitations to explain users' behaviours indicate that this model is incapable of sufficiently predicting ICT acceptance (Ajibade, 2018). For example, the TAM model is inconsistent in providing precursors to mobile use and social influence that facilitate behaviours (Ajibade, 2018). Against this backdrop, a unique customised theorisation (i.e., Expectation Disconfirmation Theory (EDT) and TAM) can be put forward for future research to conceptualise patients' acceptance of the context of telemedicine.

Furthermore, in line with EDT and TAM research, Lankton and McKnight (2012) revealed that if an easy-to-use system/service may satisfy the users, in turn, individuals may put up with a technology/system that is not easy to use. This indicates that an individual's acceptance decision will increase more for positive ease of use than it will decrease for negative ease of use regarding a system/service (Lankton \& McKnight, 2012). Lankton and McKnight (2012) further predicted that a positive asymmetry effect on ease of use would exist for performance because ease of use is more likely to have assimilation effects on satisfaction through performance than contrast effects through disconfirmation. This indicates that an individual with low experience is more likely to explore small discrepancies between ease-of-use expectations and performance disconfirmation (Lankton \& McKnight, 2012).

Some other limitations do exist in this research. First, this study reflected only the behavioural adoption intentions of health seekers. Future research should investigate factors concerning the behavioural intentions of public health providers that influence telemedicine adoption in rural settings. Second, only public telemedicine health systems were included in this study. Private telemedicine health systems could be included in future research to examine the differences between public and private service interests. Third, this study focused on few factors to determine health seekers' behavioural intentions to use telemedicine. Future research could be conducted by including age, gender, education, disease types, health literacy and organisational effects that may significantly influence health seekers' adoption intentions. Finally, this study was limited to Bangladesh. Combining this study with cross-sectional data from similar developing countries would provide a broader view of behavioural intention to use telemedicine in a global context.

\subsection{Conclusion}

This research demonstrates significant support for the proposed theorised model, accounting for over $65 \%$ of the variance in health seekers' behavioural intentions to use telemedicine healthcare services. This study has developed an extended TAM framework that has yielded guidelines for accelerating telemedicine adoption in rural Bangladesh and contextually similar settings. Drawing from research on TAM in e-Health, Hoque et al. (2017) found that privacy and trust have not contributed adequately to qualify as a determinant of patients' behavioural intentions, while in our study, we found that PDS strongly influences patients' intentions to use telemedicine services. This authenticates that health providers must keep patients' health data confidential and secure to ensure continued acceptance of telemedicine healthcare services in rural settings in Bangladesh. Further, this study would help to determine the model that is considered the most appropriate and beneficial standard as a benchmark for all future research on patients' behavioural intentions of telemedicine healthcare service adoption in both developed and developing countries' rural contexts. Consistent with our findings, this study is significant and deepens the understanding of the determinants of health seekers 
behavioural intentions of other important ICT based healthcare services adoption fields such as e-Health and m-Health. Novel interpretations of large data sets in health informatics have been generated and extended a body of new knowledge in rural emerging economies settings. Pertinent implications, limitations and forthcoming research directions were further recommended to secure the long-term sustainability of telemedicine healthcare projects in emerging economies and similar settings.

\section{Acknowledgements}

We are very grateful to all the study participants and officials of the Directorate General of Health Services under the Ministry of Health and Family Welfare of Bangladesh, who helped a lot during data collection.

\section{References}

Agarwal, R., Sambamurthy, V., \& Stair, R. M. (2000). The evolving relationship between general and specific computer self-efficacy-An empirical assessment. Information Systems Research, 11(4), 418-430.

Aggelidis, V. P., \& Chatzoglou, P. D. (2009). Using a modified technology acceptance model in hospitals. International Journal of Medical Mnformatics, 78(2), 115-126.

Ahmed, T., Bloom, G., Iqbal, M., Lucas, H., Rasheed, S., Waldman, L., . . Bhuiya, A. (2014). Ehealth and M-Health in Bangladesh: Opportunities and Challenges. Retrieved from https://www.ids.ac.uk/publications/e-health-and-m-health-in-bangladeshopportunities-and-challenges/,

Ajibade, P. (2018). Technology acceptance model limitations and criticisms: Exploring the practical applications and use in technology-related studies, mixed-method, and qualitative researches. Library Philosophy \& Practice, 1941.

Akter, S., D'Ambra, J., \& Ray, P. (2010). Service quality of mHealth platforms: development and validation of a hierarchical model using PLS. Electronic Markets, 20(3-4), 209-227.

Alam, M. Z., Hoque, M. R., Hu, W., \& Barua, Z. (2020). Factors influencing the adoption of mHealth services in a developing country: A patient-centric study. International Journal of Information Management, 50, 128-143.

Ali, I., Ali, M., Badghish, S., \& Baazeem, T. A. S. (2018). Examining the role of childhood experiences in developing altruistic and knowledge sharing behaviors among children in their later life: A partial least squares (PLS) path modeling approach. Sustainability, 10(2), 292.

Alshammari, S. H., \& Rosli, M. S. (2020). A Review of Technology Acceptance Models and Theories. Innovative Teaching and Learning Journal (ITLJ), 4(2), 12-22.

Anderberg, P., Eivazzadeh, S., \& Berglund, J. S. (2019). A Novel Instrument for Measuring Older People's Attitudes Toward Technology (TechPH): Development and Validation. Journal of Medical Internet research, 21(5), e13951. doi: 10.2196/13951

Astrachan, C. B., Patel, V. K., \& Wanzenried, G. (2014). A comparative study of CB-SEM and PLS-SEM for theory development in family firm research. Journal of Family Business Strategy, 5(1), 116-128.

Bandura, A. (1977). Self-efficacy: toward a unifying theory of behavioral change. Psychological review, 84(2), 191. https://doi.org/10.1037/0033-295X.84.2.191

Bandura, A. (1986). Social foundations of thought and action. Englewood Cliffs, New Jersey, Prentice Hall, 1986. 
Bandura, A., O'Leary, A., Taylor, C. B., Gauthier, J., \& Gossard, D. (1987). Perceived SelfEfficacy and Pain Control: Opioid and Nonopioid Mechanisms. Journal of Personality and Social Psychology, 53(3), 563-571. doi:10.1037/0022-3514.53.3.563.

Benitez, J., Henseler, J., Castillo, A., \& Schuberth, F. (2020). How to perform and report an impactful analysis using partial least squares: Guidelines for confirmatory and explanatory IS research. Information $\mathcal{E}$ Management, 57(2), 103168. https://doi.org/10.1016/j.im.2019.05.003

Bettiga, D., Lamberti, L., \& Lettieri, E. (2019). Individuals' adoption of smart technologies for preventive health care: a structural equation modeling approach. Health Care Management Science, 23(2), 203-214. doi:10.1007/s10729-019-09468-2

Bhattacherjee, A., \& Hikmet, N. (2007). Physicians' resistance toward healthcare information technology: a theoretical model and empirical test. European Journal of Information Systems, 16(6), 725-737.

Boscarino, J. A. (1992). The public's perception of quality hospitals II: Implications for patient surveys. Journal of Healthcare Management, 37(1), 13.

Bros, J. S., Poulet, C., Arnol, N., Deschaux, C., Gandit, M., \& Charavel, M. (2018). Acceptance of Telemonitoring Among Patients with Obstructive Sleep Apnea Syndrome: How is the Perceived Interest by and for Patients? Telemedicine and e-Health, 24(5), 351-359.

Chang, H. (2015). Evaluation framework for telemedicine using the logical framework approach and a fishbone diagram. Healthcare Informatics Research, 21(4), 230-238.

Chang, Y.-Z., Ko, C.-Y., Hsiao, C.-J., Chen, R.-J., Yu, C.-W., Cheng, Y.-W., . . Chao, C.-M. (2015). Understanding the determinants of implementing telehealth systems: a combined model of the theory of planned behavior and the technology acceptance model. Journal of Applied Sciences, 15(2), 277.

Chau, P. Y., \& Hu, P. J.-H. (2002). Investigating healthcare professionals' decisions to accept telemedicine technology: an empirical test of competing theories. Information $\mathcal{E}$ Management, 39(4), 297-311.

Chellappa, R. K., \& Sin, R. G. (2005). Personalization versus privacy: An empirical examination of the online consumer's dilemma. Information Technology and Management, 6(2-3), 181202.

Chen, R.-F., \& Hsiao, J.-L. (2012). An empirical study of physicians' acceptance of hospital information systems in Taiwan. Telemedicine and e-Health, 18(2), 120-125.

Cheng, T. L., Savageau, J. A., Sattler, A. L., \& DeWitt, T. G. (1993). Confidentiality in health care: a survey of knowledge, perceptions, and attitudes among high school students. JAMA, 269(11), 1404-1407.

Chin, W. W. (1998). The partial least squares approach to structural equation modeling. Modern Methods for Business Research, 295(2), 295-336.

Cimperman, M., Brenčič, M. M., \& Trkman, P. (2016). Analyzing older users' home telehealth services acceptance behavior-applying an Extended UTAUT model. International Journal of Medical Informatics, 90, 22-31.

Cresswell, J. W., \& Clark, V. L. P. (2011). Designing and conducting mixed methods resaerch. (2nd edition). Thousand Oaks, California, SAGE, 2011.

Cronin Jr, J. J., Brady, M. K., \& Hult, G. T. M. (2000). Assessing the effects of quality, value, and customer satisfaction on consumer behavioral intentions in service environments. Journal of Retailing, 76(2), 193-218. 
Culnan, M. J., \& Armstrong, P. K. (1999). Information Privacy Concerns, Procedural Fairness, and Impersonal Trust: An Empirical Investigation. Organization Science, 10(1), 104-115. doi:10.1287/orsc.10.1.104.

Darkwa, E. K., Newman, M. S., Kawkab, M., \& Chowdhury, M. E. (2015). A qualitative study of factors influencing retention of doctors and nurses at rural healthcare facilities in Bangladesh. BMC Health Services Research, 15(1), 344. doi:10.1186/s12913-015-1012-z.

Davis, L.E., Harnar, J., LaChey-Barbee, L. A., Pirio Richardson, S., Fraser, A., \& King, M. K. (2019). Using teleneurology to deliver chronic neurologic care to rural veterans: analysis of the first 1,100 patient visits. Telemedicine and e-Health, 25(4), 274-278.

Davis, F. D. (1989). Perceived usefulness, perceived ease of use, and user acceptance of information technology. MIS Quarterly, 13(3), 319-340. https://doi.org/10.2307/249008

Davis, F. D., Bagozzi, R. P., \& Warshaw, P. R. (1989). User Acceptance of Computer Technology: A Comparison of Two Theoretical Models. Management Science, 35(8), 9821003. doi:10.1287/mnsc.35.8.982.

Delone, W. H., \& McLean, E. R. (2003). The DeLone and McLean model of information systems success: a ten-year update. Journal of Management Information Systems, 19(4), 9-30.

Dijkstra, T. K., \& Henseler, J. (2015). Consistent and asymptotically normal PLS estimators for linear structural equations. Computational Statistics \& Data Analysis, 81, 10-23.

Dünnebeil, S., Sunyaev, A., Blohm, I., Leimeister, J. M., \& Krcmar, H. (2012). Determinants of physicians' technology acceptance for e-health in ambulatory care. International Journal of Medical Informatics, 81(11), 746-760. doi:10.1016/j.ijmedinf.2012.02.002.

Dutot, V., Bergeron, F., Rozhkova, K., \& Moreau, N. (2019). Factors Affecting the Adoption of Connected Objects in e-Health: A Mixed Methods Approach. Systèmes d'Information et Management, 23(4), 31-66. https://aisel.aisnet.org/sim/vol23/iss4/7

Dwivedi, Y. K., Shareef, M. A., Simintiras, A. C., Lal, B., \& Weerakkody, V. (2016). A generalised adoption model for services: A cross-country comparison of mobile health (m-health). Government Information Quarterly, 33(1), 174-187.

Esmaeilzadeh, P. (2019). The effects of public concern for information privacy on the adoption of Health Information Exchanges (HIEs) by healthcare entities. Health Communication, 34(10), 1202-1211.

Evans, P. R. (2015). An exploration of the perceptions of a US Midwest acute care hospital organization regarding the adoption and acceptance of telemedicine. (Doctoral dissertaion, Capella University), ProQuest Dissertations Publishing, 2015. 3700252.

Ferrer-Roca, O., Garcia-Nogales, A., \& Pelaez, C. (2010). The impact of telemedicine on quality of life in rural areas: the Extremadura model of specialized care delivery. Telemedicine and e-Health, 16(2), 233-243.

Gefen, D., Straub, D., \& Boudreau, M.-C. (2000). Structural equation modeling and regression: Guidelines for research practice. Communications of the Association for Information Systems, 4(1), 7. https://doi.org/10.17705/1CAIS.00407

Greenberg, A. S., Steinway, C., Wu, K., Thomas, B., Chuo, J., DiGiovine, M., \& Jan, S. J. J. o. A. H. (2019). 80. Role of Telemedicine in the Transition From Pediatric To Adult Care. 64(2), S43.

Hair, J., Hair, J., Hollingsworth, C. L., Hollingsworth, C. L., Randolph, A. B., Randolph, A. B., ... Chong, A. Y. L. (2017). An updated and expanded assessment of PLS-SEM in information systems research. Industrial Management \& Data Systems, 117(3), 442-458.

Hair, J. F., Ringle, C. M., \& Sarstedt, M. (2011). PLS-SEM: Indeed a silver bullet. Journal of Marketing Theory and Practice, 19(2), 139-152. 
Hair, J. F., Ringle, C. M., \& Sarstedt, M. (2013). Partial least squares structural equation modeling: Rigorous applications, better results and higher acceptance. Long Range Planning, 46(1-2), 1-12.

Hair Jr, J. F., Howard, M. C., \& Nitzl, C. (2020). Assessing measurement model quality in PLSSEM using confirmatory composite analysis. Journal of Business Research, 109, 101-110.

Hair Jr, J. F., Hult, G. T. M., Ringle, C., \& Sarstedt, M. (2016). A primer on partial least squares structural equation modeling (PLS-SEM): Los Angeles, California, Sage Publications.

Hair Jr, J. F., Hult, G. T. M., Ringle, C., \& Sarstedt, M. (2017). A primer on partial least squares structural equation modeling (PLS-SEM): Los Angeles, California, Sage Publications.

Hale, T. M., \& Kvedar, J. C. (2014). Privacy and security concerns in telehealth. Virtual Mentor, 16(12), 981.

Hall, J. L., \& McGraw, D. (2014). For telehealth to succeed, privacy and security risks must be identified and addressed. Health Qffairs, 33(2), 216-221.

Henseler, J., Hubona, G., \& Ray, P. A. (2017). Partial least squares path modeling: Updated guidelines. In Partial Least Squares Path Modeling (pp. 19-39): Cham, Switzerland Springer. 10.1007/978-3-319-64069-3_2

Henseler, J., Ringle, C. M., \& Sinkovics, R. R. (2009). The use of partial least squares path modeling in international marketing. In New challenges to international marketing (pp. 277319): Bingley, Emerald Group Publishing Limited. doi: 10.1108/S1474-7979(2009)0000020014

Hill, M. H., \& Doddato, T. (2002). Relationships among patient satisfaction, intent to return, and intent to recommend services provided by an academic nursing center. Journal of Cultural Diversity, 9(4), 108-112.

Holden, R. J., \& Karsh, B.-T. (2010). The technology acceptance model: its past and its future in health care. Journal of Biomedical Informatics, 43(1), 159-172.

Hoque, Bao, Y., \& Sorwar, G. (2017). Investigating factors influencing the adoption of e-Health in developing countries: A patient's perspective. Informatics for Health and Social Care, 42(1), 1-17.

Hoque, \& Sorwar, G. (2017). Understanding factors influencing the adoption of mHealth by the elderly: An extension of the UTAUT model. International Journal of Medical Informatics, 101, 75-84. doi:10.1016/j.ijmedinf.2017.02.002.

Hossain, A., Quaresma, R., \& Rahman, H. (2019). Investigating factors influencing the physicians' adoption of electronic health record (EHR) in healthcare system of Bangladesh: An empirical study. International Journal of Information Management, 44, 7687.

Hsia, T.-L., Chiang, A.-J., Wu, J.-H., Teng, N. N., \& Rubin, A. D. (2019). What Drives E-Health Usage? Integrated Institutional Forces and Top Management Perspectives. Computers in Human Behavior.

Hu, P. J., Chau, P. Y., Sheng, O. R. L., \& Tam, K. Y. (1999). Examining the technology acceptance model using physician acceptance of telemedicine technology. Journal of Management Information Systems, 16(2), 91-112.

Hur, I., Cousins, K. C., \& Stahl, B. C. (2019). A critical perspective of engagement in online health communities. European Journal of Information Systems, 28(5), 523-548. https://doi.org/10.1080/0960085X.2019.1620477

Islam, F., Rahman, A., Halim, A., Eriksson, C., Rahman, F., \& Dalal, K. (2015). Perceptions of health care providers and patients on quality of care in maternal and neonatal health in fourteen Bangladesh government healthcare facilities: a mixed-method study. BMC Health Services Research, 15(1), 1-9. doi: 10.1186/s12913-015-0918-9 
Ivatury, G., Moore, J., \& Bloch, A. (2009). A doctor in your pocket: health hotlines in developing countries. Innovations: Technology, Governance, Globalization, 4(1), 119-153.

Jansen-Kosterink, S., Dekker-van Weering, M., \& van Velsen, L. (2019). Patient acceptance of a telemedicine service for rehabilitation care: A focus group study. International Journal of Medical Informatics, 125, 22-29.

Jewer, J. (2018). Patients' intention to use online postings of ED wait times: A modified UTAUT model. International Journal of Medical Informatics 112, 34-39. https://doi.org/10.1016/j.ijmedinf.2018.01.008

Johnston, A. C., \& Warkentin, M. (2010). Fear appeals and information security behaviors: an empirical study. MIS Quarterly, 34(3), 549-566. https://doi.org/10.2307/25750691

Kamal, S. A., Shafiq, M., \& Kakria, P. (2020). Investigating acceptance of telemedicine services through an extended technology acceptance model (TAM). Technology in Society, 60, 101212.

Karahanna, E., \& Straub, D. W. (1999). The psychological origins of perceived usefulness and ease-of-use. Information \& Management, 35(4), 237-250.

Kettinger, W. J., \& Lee, C. C. (1997). Pragmatic Perspectives on the Measurement of Information Systems Service Quality. MIS Quarterly, 21(2), 223-240.

Kim, \& Park, H.-A. (2012). Development of a health information technology acceptance model using consumers' health behavior intention. Journal of Medical Internet Research, 14(5), e133. doi: 10.2196/jmir.2143

Kim, K.-H., Kim, K.-J., Lee, D.-H., \& Kim, M.-G. (2019). Identification of critical quality dimensions for continuance intention in mHealth services: Case study of onecare service. International Journal of Information Management, 46, 187-197.

Koceska, N., Komadina, R., Simjanoska, M., Koteska, B., Strahovnik, A., Jošt, A., . . Trontelj, J. (2019). Mobile wireless monitoring system for prehospital emergency care. European Journal of Trauma and Emergency Surgery, 46(6), 1301-1308.

Kock, N. (2018). Should bootstrapping be used in PLS-SEM? Toward stable P-Value calculation methods. Journal of Applied Structural Equation Modeling, 2(1), 1-12.

Kuruvilla, S., Mays, N., Pleasant, A., \& Walt, G. (2006). Describing the impact of health research: a Research Impact Framework. BMC Health Services Research, 6(1), 1-18.

Lankton, N. K., \& McKnight, H. D. (2012). Examining two expectation disconfirmation theory models: assimilation and asymmetry effects. Journal of the Association for Information Systems, 13(2), 1. DOI: 10.17705/1jais.00285

Lankton, N. K., \& Wilson, E. V. (2007). Factors influencing expectations of e-health services within a direct-effects model of user satisfaction. E-Service Journal, 5(2), 85-112.

Lending, D., \& Dillon, T. W. (2007). The effects of confidentiality on nursing self-efficacy with information systems. International Journal of Healthcare Information Systems and Informatics (IJHISI), 2(3), 49-64.

LeRouge, C., \& Garfield, M. J. (2013). Crossing the telemedicine chasm: have the US barriers to widespread adoption of telemedicine been significantly reduced? International Journal of Environmental Research and Public Health, 10(12), 6472-6484.

LeRouge, C. M., Gupta, M., Corpart, G., \& Arrieta, A. (2019). Health System Approaches Are Needed to Expand Telemedicine Use Across Nine Latin American Nations. Health Affairs, 38(2), 212-221.

Leung, L., \& Chen, C. (2019). E-health/m-health adoption and lifestyle improvements: Exploring the roles of technology readiness, the expectation-confirmation model, and health-related information activities. Telecommunications Policy, 43(6), 563-575. 
Lewis, W., Agarwal, R., \& Sambamurthy, V. (2003). Sources of influence on beliefs about information technology use: An empirical study of knowledge workers. MIS Quarterly, 27(4), 657-678. https://doi.org/10.2307/30036552

Lin, H.-C., \& Chang, C.-M. (2018). What motivates health information exchange in social media? The roles of the social cognitive theory and perceived interactivity. Information $\mathcal{E}$ Management, 55(6), 771-780. https://doi.org/10.1016/j.im.2018.03.006

Lu, J., Yao, J. E., \& Yu, C.-S. (2005). Personal innovativeness, social influences and adoption of wireless Internet services via mobile technology. The Journal of Strategic Information Systems, 14(3), 245-268.

Macedo, I. M. (2017). Predicting the acceptance and use of information and communication technology by older adults: An empirical examination of the revised UTAUT2. Computers in Human Behavior, 75, 935-948.

Maillet, É., Mathieu, L., \& Sicotte, C. (2015). Modeling factors explaining the acceptance, actual use and satisfaction of nurses using an Electronic Patient Record in acute care settings: An extension of the UTAUT. International Journal of Medical Informatics, 84(1), 36-47.

Muthupoltotage, U. P., \& Gardner, L. (2018). Analysing the Relationships Between Digital Literacy and Self-Regulated Learning of Undergraduates-A Preliminary Investigation. In Advances in Information Systems Development (pp. 1-16): Cham, Switzerland, Springer.

Or, C. K., Karsh, B.-T., Severtson, D. J., Burke, L. J., Brown, R. L., \& Brennan, P. F. (2011). Factors affecting home care patients' acceptance of a web-based interactive self-management technology. Journal of the American Medical Informatics Association, 18(1), 51-59.

Otter, V., \& Beer, L. (2021). Alley cropping systems as Ecological Focus Areas: A PLS-analysis of German farmers' acceptance behaviour. Journal of Cleaner Production, 280, 123702. https://doi.org/10.1016/j.jclepro.2020.123702

Parasuraman, A., Zeithaml, V. A., \& Berry, L. L. (1985). A conceptual model of service quality and its implications for future research. The Journal of Marketing, 49(4), 41-50.

Ramkumar, M., Schoenherr, T., Wagner, S. M., \& Jenamani, M. (2019). Q-TAM: A quality technology acceptance model for predicting organizational buyers' continuance intentions for e-procurement services. International Journal of Production Economics, 216, 333-348.

Rho, M. J., young Choi, I., \& Lee, J. (2014). Predictive factors of telemedicine service acceptance and behavioral intention of physicians. International Journal of Medical Informatics, 83(8), 559-571.

Ringle, C. M., Sarstedt, M., \& Straub, D. W. (2012). Editor's comments: a critical look at the use of PLS-SEM in MIS quarterly. MIS Quarterly, 36(1), iii-xiv.

Roldán, J. L., \& Sánchez-Franco, M. J. (2012). Variance-based structural equation modeling: guidelines for using partial least squares. Research methodologies, innovations and philosophies in software systems engineering and information systems, (pp.193-221). IGI Global. doi: 10.4018/978-1-4666-0179-6.ch010

Rosenstock, I. M., Strecher, V. J., \& Becker, M. H. (1988). Social learning theory and the health belief model. Health Education Quarterly, 15(2), 175-183.

Schuberth, F., Henseler, J., \& Dijkstra, T. K. (2018). Partial least squares path modeling using ordinal categorical indicators. Quality \& Quantity, 52(1), 9-35.

Schubring, S., Lorscheid, I., Meyer, M., \& Ringle, C. M. (2016). The PLS agent: Predictive modeling with PLS-SEM and agent-based simulation. Journal of Business Research, 69(10), 4604-4612. 
Shankar, V., Smith, A. K., \& Rangaswamy, A. (2003). Customer satisfaction and loyalty in online and offline environments. International Journal of Research in Marketing, 20(2), 153175.

Taylor, J., Coates, E., Wessels, B., Mountain, G., \& Hawley, M. S. (2015). Implementing solutions to improve and expand telehealth adoption: participatory action research in four community healthcare settings. BMC Health Services Research, 15(1), 529.

Tsai, C.-H. (2014). Integrating social capital theory, social cognitive theory, and the technology acceptance model to explore a behavioral model of telehealth systems. International Journal of Environmental Research and Public Health, 11(5), 4905-4925.

Venkatesh, V. (2000a). Determinants of perceived ease of use: Integrating control, intrinsic motivation, and emotion into the technology acceptance model. Information Systems Research, 11(4), 342-365.

Venkatesh, V. (2000b). Determinants of perceived ease of use: Integrating perceived behavioral control, computer anxiety and enjoyment into the technology acceptance model. Information Systems Research, 11(4), 342-365.

Venkatesh, V., \& Bala, H. (2008). Technology acceptance model 3 and a research agenda on interventions. Decision Sciences, 39(2), 273-315.

Venkatesh, V., \& Davis, F. D. (1996). A model of the antecedents of perceived ease of use: Development and test. Decision Sciences, 27(3), 451-481.

Venkatesh, V., \& Davis, F. D. (2000). A theoretical extension of the technology acceptance model: Four longitudinal field studies. Management Science, 46(2), 186-204.

Venkatesh, V., Morris, M. G., Davis, G. B., \& Davis, F. D. (2003). User acceptance of information technology: Toward a unified view. MIS Quarterly, 27(3), 425-478. https://doi.org/10.2307/30036540

Venkatesh, V., Thong, J. Y., \& Xu, X. (2012). Consumer acceptance and use of information technology: extending the unified theory of acceptance and use of technology. MIS Quarterly, 36(1), 157-178. https://doi.org/10.2307/41410412

Vries, H. D., Backbier, E., Kok, G., \& Dijkstra, M. (1995). The Impact of Social Influences in the Context of Attitude, Self-Efficacy, Intention, and Previous Behavior as Predictors of Smoking Onset. Journal of Applied Social Psychology, 25(3), 237-257.

Whitten, P., Holtz, B., \& Nguyen, L. (2010). Keys to a successful and sustainable telemedicine program. International Journal of Technology Assessment in Health Care, 26(2), 211-216. doi: https://doi.org/10.1017/S026646231000005X

Wilkowska, W., \& Ziefle, M. (2011). Perception of privacy and security for acceptance of E-health technologies: Exploratory analysis for diverse user groups. In $20115^{\text {th }}$ International Conference on Pervasive Computing Technologies for Healthcare (PervasiveHealth) and Workshop (pp. 593-600). IEEE. doi: 10.4108/icst.pervasivehealth.2011.246027

Williams, K., \& Bond, M. (2002). The roles of self-efficacy, outcome expectancies and social support in the self-care behaviours of diabetics. Psychology, Health $\mathcal{E}$ Medicine, 7(2), 127141.

Wilson, B. (2010). Using PLS to investigate interaction effects between higher order branding constructs. In Handbook of Partial Least Squares (pp. 621-652): Berlin, Heidelberg, Germany, Springer. doi: 10.1007/978-3-540-32827-8_28

Woo, K., \& Dowding, D. (2018). Factors Affecting the Acceptance of Telehealth Services by Heart Failure Patients: An Integrative Review. Telemedicine and e-Health, 24(4), 292-300. 
Wu, J.-H., Shen, W.-S., Lin, L.-M., Greenes, R. A., \& Bates, D. W. (2008). Testing the technology acceptance model for evaluating healthcare professionals' intention to use an adverse event reporting system. International Journal for Quality in Health Care, 20(2), 123-129.

$\mathrm{Xu}, \mathrm{Z}$. (2019). An empirical study of patients' privacy concerns for health informatics as a service. Technological Forecasting and Social Change, 143, 297-306.

Yarbrough, A. K., \& Smith, T. B. (2007). Technology acceptance among physicians: a new take on TAM. Medical Care Research and Review, 64(6), 650-672.

Zeithaml, V. A., Berry, L. L., \& Parasuraman, A. (1996). The behavioral consequences of service quality. Journal of Marketing, 60(2), 31-46.

Zhang, X., Han, X., Dang, Y., Meng, F., Guo, X., \& Lin, J. (2017). User acceptance of mobile health services from users' perspectives: The role of self-efficacy and response-efficacy in technology acceptance. Informatics for Health and Social Care, 42(2), 194-206.

Zhou, M., Zhao, L., Kong, N., Campy, K. S., Qu, S., \& Wang, S. (2019). Factors influencing behavior intentions to telehealth by Chinese elderly: An extended TAM model. International Journal of Medical Informatics, 126, 118-127.

Zobair, K. M., Sanzogni, L., \& Sandhu, K. (2019). Expectations of telemedicine health service adoption in rural Bangladesh. Social Science $\mathcal{E}$ Medicine, 238, 112485. https://doi.org/10.1016/j.socscimed.2019.112485

Zobair, K. M., Sanzogni, L., Sandhu, K., \& Islam, M. J. (2020). Telemedicine Adoption Opportunities and Challenges in the Developing World. In Evaluating Challenges and Opportunities for Healthcare Reform (pp. 167-193): Hershey, PE, USA, IGI Global. doi: 10.4018/978-1-7998-8052-3.ch003

\section{Appendix}

Measurement items of constructs

\begin{tabular}{|c|c|c|c|}
\hline Constructs & Indicators & Statement & Sources \\
\hline \multirow[t]{4}{*}{$\begin{array}{l}\text { Perceived } \\
\text { Usefulness } \\
\text { (PU) }\end{array}$} & PU1 & Using telemedicine will improve my quality of life. & \multirow{4}{*}{$\begin{array}{l}\text { (Bhattacherjee \& } \\
\text { Hikmet, 2007; Chau \& } \\
\text { Hu, 2002; Hoque et al., } \\
\text { 2017; Venkatesh et al., } \\
\text { 2003) }\end{array}$} \\
\hline & PU2 & Using telemedicine will make my life more convenient. & \\
\hline & PU3 & $\begin{array}{l}\text { Using telemedicine will make me more productive in } \\
\text { managing my health. }\end{array}$ & \\
\hline & PU4 & Using telemedicine will make my life more useful. & \\
\hline \multirow[t]{3}{*}{$\begin{array}{l}\text { Perceived } \\
\text { Ease of Use } \\
(\mathrm{PEU}) \\
\end{array}$} & PEU1 & I can get telemedicine health services easily. & \multirow[t]{3}{*}{$\begin{array}{l}\text { (Chau \& Hu, 2002; } \\
\text { Venkatesh et al., 2003; } \\
\text { Zhou et al., 2019) }\end{array}$} \\
\hline & PEU2 & $\begin{array}{l}\text { I can easily receive a remotely specialist consultation } \\
\text { via telemedicine. }\end{array}$ & \\
\hline & PEU3 & $\begin{array}{l}\text { I can discuss my health-related issues with specialist } \\
\text { physicians easily via video conferencing. }\end{array}$ & \\
\hline
\end{tabular}




\begin{tabular}{|c|c|c|c|}
\hline & PEU4 & $\begin{array}{l}\text { Using telemedicine to discuss with my specialist } \\
\text { physician, any of my health-related issues is easy for } \\
\text { me. }\end{array}$ & \\
\hline \multirow[t]{4}{*}{$\begin{array}{l}\text { Self-Efficacy } \\
\text { (SE) }\end{array}$} & SE1 & $\begin{array}{l}\text { It is easy for me to get telemedicine services that are } \\
\text { provided by my hospitals. }\end{array}$ & \multirow{4}{*}{$\begin{array}{l}\text { (Johnston \& Warkentin, } \\
\text { 2010; Maillet et al., } \\
\text { 2015; Tsai, 2014; } \\
\text { Venkatesh et al., 2003; } \\
\text { Zhang et al., 2017) }\end{array}$} \\
\hline & SE2 & $\begin{array}{l}\text { I can use telemedicine for receiving specialist } \\
\text { consultation remotely. }\end{array}$ & \\
\hline & SE3 & $\begin{array}{l}\text { I am confident to discuss my health-related issue with } \\
\text { specialists via telemedicine. }\end{array}$ & \\
\hline & SE4 & $\begin{array}{l}\text { I believe that I can use telemedicine for better health } \\
\text { management. }\end{array}$ & \\
\hline \multirow[t]{6}{*}{$\begin{array}{l}\text { Service } \\
\text { Quality (SQ) }\end{array}$} & SQ1 & $\begin{array}{l}\text { I have been satisfied with telemedicine services that } \\
\text { performed well for the first time. }\end{array}$ & $\begin{array}{l}\text { (Akter et al., 2010; } \\
\text { Kettinger \& Lee, 1997) }\end{array}$ \\
\hline & SQ2 & $\begin{array}{l}\text { Getting telemedicine has enabled me to improve my } \\
\text { health. }\end{array}$ & \\
\hline & SQ3 & $\begin{array}{l}\text { In most ways, my healthy life has come closer to my } \\
\text { ideal since I have started to use telemedicine. }\end{array}$ & \\
\hline & SQ4 & $\begin{array}{l}\text { The physicians in telemedicine have understood my } \\
\text { specific health needs. }\end{array}$ & \\
\hline & SQ5 & $\begin{array}{l}\text { The physicians in telemedicine have given me } \\
\text { individual attention during the consultation. }\end{array}$ & \\
\hline & SQ6 & $\begin{array}{l}\text { Overall, telemedicine has helped me to achieve the } \\
\text { health goals I most expect in life. }\end{array}$ & \\
\hline \multirow[t]{5}{*}{$\begin{array}{l}\text { Social } \\
\text { Influence } \\
(\mathrm{SI})\end{array}$} & SI1 & $\begin{array}{l}\text { People who are important to me think that I should use } \\
\text { telemedicine. }\end{array}$ & \multirow{5}{*}{$\begin{array}{l}\text { (Dwivedi, Shareef, } \\
\text { Simintiras, Lal, \& } \\
\text { Weerakkody, 2016; } \\
\text { Hoque \& Sorwar, 2017; } \\
\text { Venkatesh et al., 2003) }\end{array}$} \\
\hline & SI2 & $\begin{array}{l}\text { People who influence my behaviour think that I should } \\
\text { use telemedicine. }\end{array}$ & \\
\hline & SI3 & $\begin{array}{l}\text { Those family members who are important to me think } \\
\text { I should use telemedicine. }\end{array}$ & \\
\hline & SI4 & $\begin{array}{l}\text { My friends whose opinions I value think I should use } \\
\text { telemedicine. }\end{array}$ & \\
\hline & SI5 & $\begin{array}{l}\text { The physicians whose opinions I value prefer that I } \\
\text { should use telemedicine. }\end{array}$ & \\
\hline \multirow[t]{3}{*}{$\begin{array}{l}\text { Privacy and } \\
\text { Data } \\
\text { Security } \\
\text { (PDS) } \\
\end{array}$} & PDS1 & $\begin{array}{l}\text { I believe the privacy of telemedicine patients is } \\
\text { protected. }\end{array}$ & \multirow{3}{*}{$\begin{array}{l}\text { (Chellappa \& Sin, 2005; } \\
\text { Culnan \& Armstrong, } \\
\text { 1999; Dünnebeil, } \\
\text { Sunyaev, Blohm, } \\
\text { Leimeister, \& Krcmar, } \\
\text { 2012; Hoque et al., 2017) }\end{array}$} \\
\hline & PDS2 & $\begin{array}{l}\text { I believe that the personal information stored in the } \\
\text { telemedicine system is safe. }\end{array}$ & \\
\hline & PDS3 & $\begin{array}{l}\text { I believe the telemedicine system keeps patients' } \\
\text { information secure. }\end{array}$ & \\
\hline $\begin{array}{l}\text { Facilitating } \\
\text { Condition } \\
(\mathrm{FC})\end{array}$ & FC1 & $\begin{array}{l}\text { I find that telemedicine has the resources necessary to } \\
\text { provide me with healthcare services. }\end{array}$ & $\begin{array}{l}\text { (Alam et al., 2020; } \\
\text { Dwivedi et al., 2016; }\end{array}$ \\
\hline
\end{tabular}




\begin{tabular}{|c|c|c|c|}
\hline & FC2 & $\begin{array}{l}\text { I find that telemedicine physicians have been very } \\
\text { knowledgeable. }\end{array}$ & \multirow[t]{5}{*}{$\begin{array}{l}\text { Hoque \& Sorwar, 2017; } \\
\text { Venkatesh et al., 2003) }\end{array}$} \\
\hline & FC3 & $\begin{array}{l}\text { I find that telemedicine facilitates the required } \\
\text { technologies that are needed. }\end{array}$ & \\
\hline & FC4 & I can get telemedicine services when I need to. & \\
\hline & FC5 & $\begin{array}{l}\text { I find that telemedicine enables easy referrals to } \\
\text { specialised physicians. }\end{array}$ & \\
\hline & FC6 & I have found telemedicine consultations successful. & \\
\hline \multirow[t]{4}{*}{$\begin{array}{l}\text { Behavioural } \\
\text { Intention } \\
(\mathrm{BI})\end{array}$} & BI1 & I have a high intention to use telemedicine. & \multirow{4}{*}{$\begin{array}{l}\text { (Chau \& Hu, 2002; } \\
\text { Hoque \& Sorwar, 2017; } \\
\text { Venkatesh et al., 2003; } \\
\text { Zhou et al., 2019) }\end{array}$} \\
\hline & BI2 & I intend to use telemedicine for a better quality of life. & \\
\hline & $\mathrm{BI} 3$ & $\begin{array}{l}\text { I intend to acquire more knowledge about the benefits } \\
\text { of telemedicine for better health management. }\end{array}$ & \\
\hline & BI4 & I plan to use telemedicine to manage my healthy life. & \\
\hline
\end{tabular}

Copyright: (C) 2021 authors. This is an open-access article distributed under the terms of the Creative Commons Attribution-NonCommercial 3.0 Australia License, which permits noncommercial use, distribution, and reproduction in any medium, provided the original author and AJIS are credited.

doi: https://doi.org/10.3127/ajis.v25i0.3071

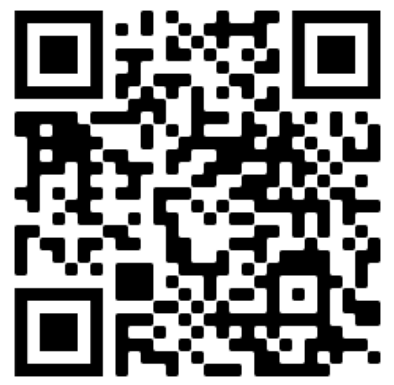

